\title{
Nonlinear dynamic behaviour of severely corroded reinforced concrete columns: shaking table study
}

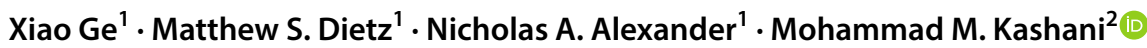

Received: 13 June 2019 / Accepted: 1 November 2019 / Published online: 8 November 2019

(c) The Author(s) 2019

\begin{abstract}
A set of benchmark, medium scale, shaking table tests on corroded reinforced concrete (RC) columns is conducted with the aim of investigating the effects of corrosion damage on the nonlinear dynamic behaviour of RC bridge piers. The experimental programme consists of an uncorroded control specimen and two corroded RC column specimens, with identical structural details. An accelerated corrosion procedure is used to corrode the RC columns. The uncorroded and corroded specimens are subjected to far-field long duration ground motion excitations. The two corroded columns had 51\% and $65 \%$ average mass loss ratios. The testing sequence includes slight, extensive, and complete damage levels, followed by an aftershock to examine the cascade effect on the nonlinear dynamic response of the proposed RC columns. The experimental results show that corrosion changes the failure mode of the RC columns, and has a significant negative impact on the residual strength (about 50\% mass loss results in about $80 \%$ strength reduction) and drift capacity of RC columns.
\end{abstract}

Keywords Shaking table test $\cdot$ Corrosion $\cdot$ Reinforced concrete column $\cdot$ Accelerated corrosion $\cdot$ Nonlinear dynamic response

\section{Introduction}

Material deterioration, induced by corrosion, is a significant hazard to the durability of reinforced concrete (RC) structures and increases their vulnerability to seismic events (ASCE 2013). This is especially the case for those either in the marine environment or transport structures expose to de-icing salt (Chiu et al. 2015). Every year, trillions of dollars are spent worldwide on repair and maintenance of corroded RC structure (Schmitt 2009). The structural performance of RC structures could be affected by corrosion through (1) degradation of the mechanical properties of the corroded reinforcing bars, (2) debonding due to the reduced bond strength between the bar and the concrete, (3) damage in concrete caused

Mohammad M. Kashani

mehdi.kashani@soton.ac.uk

1 Department of Civil Engineering, University of Bristol, Bristol BS8 1TR, UK

2 Faculty of Engineering and Physical Sciences, University of Southampton,

Southampton SO17 1BJ, UK 
by volumetric expansion of the corrosion products, and (4) a loss of concrete confinement due to corrosion of the confining reinforcement. As a result, the structural performance of $\mathrm{RC}$ structures is significantly affected by corrosion.

At material level, several researchers (Almusallam 2001; Du et al. 2005a, b; Kashani et al. 2013a, b, 2014; Zhu and François 2014; Fernandez et al. 2015; Kashani et al. 2015a, b; Zhang et al. 2015a; Balestra et al. 2016; Fernandez et al. 2016; Ou et al. 2016; Taha and Morsy 2016; Kashani 2017; Lim et al. 2017; Zhu et al. 2017) concluded that corrosion has a significant negative impact on the mechanical properties of reinforcing bars. Experimental material testing indicates that a significant decrease in both the yield and ultimate strengths of corroded rebars can be observed when the corrosion level is over $10 \%$ mass loss. As corrosion level increases, the ratio of the ultimate strength to yield strength of corroded bars ascends (Zhang et al. 2015a; Balestra et al. 2016; Ou et al. 2016). It is also observed by some researchers (Ou et al. 2016, Taha and Morsy 2016) that the yield plateau of the corroded bars is shortened or it even disappears when bars are heavily corroded (i.e. a reduction in total elongation of rebars). The nonuniform residual cross-section is more vulnerable to tensile loading compared with the symmetrical residual cross-section (Zhu and François 2014). Non-uniform pitting along the bar is reported as the key factor influencing the stress-strain behaviour of corroded reinforcing bars under both monotonic and cyclic loading (Almusallam 2001; Kashani et al. 2013a, b; Fernandez et al. 2015; Balestra et al. 2016; Fernandez et al. 2016; Zhu et al. 2017). Distribution of pitting also affects the inelastic buckling mechanism of the bars in compression (Kashani 2017). The tensile fracture of corroded bars observed by Kashani et al. (2013a, b) at the maximum pitted section of the corroded bar under cyclic loading, which is due to the combined impact of premature yielding in tension, inelastic buckling, and low-cycle fatigue degradation.

At the structural component level, some studies have been conducted on the structural performance of corroded RC components under static cyclic loading (Mangat and Elgarf 1999; Castel et al. 2000a, b; Webster and Clark 2000; Lee et al. 2003; El Maaddawy et al. 2005; Kallias and Rafiq 2010; Ma et al. 2012; Ou et al. 2012; Meda et al. 2014; Guo et al. 2015a, b; Li et al. 2015; Zhang et al. 2015b; Vu et al. 2016; Yang et al. 2016; Liu et al. 2017; Kashani et al. 2017a; Zhang et al. 2017; Dizaj et al. 2018a, b; Li et al. 2018; Rajput and Sharma 2018). They reported that corroded RC columns demonstrated a significant reduction in the ultimate load capacity and ductility. This degradation is attributed to the combined effect of corrosion-induced damage to both reinforcing bars and concrete. In some studies (Lee et al. 2003; Guo et al. 2015a), the reinforcing bars failed due to severe nonuniform distribution of pitting corrosion. In terms of energy dissipation capacity, Ma et al. (2012) reported that RC columns with mass loss ratios less than $14 \%$ have approximately the same cumulative energy dissipation capacity as uncorroded columns. However, Guo et al. (2015a) and $\mathrm{Li}$ et al. (2018) reported that RC columns with mass loss ratios around $5-15 \%$ have less energy dissipation capacity than uncorroded columns. Mangat and Elgarf (1999) pointed out that the flexural capacity of corroded RC beams is mainly governed by the degradation of the steel-concrete bond strength, while Castel et al. (2000a) found the mass loss of the tensile reinforcement is the primary reason accounting for the bar's capacity degradation. Several researchers reported that the transverse reinforcement is more vulnerable to corrosion damage than the longitudinal reinforcement since they have less cover than the longitudinal reinforcement. This results in premature buckling of the longitudinal reinforcement and crushing of concrete core under lateral cyclic and/or axial loadings (Ma et al. 2012; Meda et al. 2014; Kashani et al. 2017a).

Several researchers (Alipour et al. 2010; Ghosh and Padgett 2010; Guo et al. 2015a, b; Ghosh and Sood 2016; Kashani et al. 2016a, b; Ni Choine et al. 2016; Di Carlo et al. 
2017; Kashani et al. 2017a) have investigated the nonlinear static and dynamic responses of corroded RC bridges numerically. However, to date, there is no experimental data on the testing of corroded RC components under real dynamic earthquake loading. This is crucial to investigate the nonlinear dynamic response of corroded RC columns, and to validate the aforementioned numerical models.

\subsection{Research significance and contribution}

Although there have been numerous static experimental testing on corroded columns, there is a significant paucity of experimental data for the nonlinear dynamic behaviour of corroded RC columns in the literature. Accordingly, the aim of this study, and hence the main novelty of this work, is to bridge the gap between previously observed results in static experimental testing, and numerical models, by the experimental investigation of the impact of corrosion on the nonlinear dynamic response of corroded RC columns subject to real-time dynamic earthquake loading. The experimental results of static tests revealed that corrosion affects the ductility and lateral drift capacity of corroded columns. However, there is no experimental data on how this will affect the nonlinear dynamic response and dynamic characteristics of corroded columns. For example, nonuniform corrosion at crosssection levels might result in eccentricities in stiffness and damping that produce complex structural responses that are coupled in/out-of-plane even when subjected to in-plane seismic excitation. The resulting nonlinear stiffness and strength degradation, in this case of dynamic excitation, is impossible to capture using traditional quasi-static experiments.

The experimental programme consists of three lightly confined RC column specimens that represent columns of non-code conforming structures. One of the three columns is used as a control specimen (it is not corroded and is termed: UnCorr) and two columns are corroded with different mass loss ratios. A far-field (FF) long-duration ground motion record (Manjil earthquake) (see Kashani et al. 2017b for details of the ground motion selection procedure), is selected from FEMA (2009) and is used as input ground motion excitation to the shake table. The specimens are tested with ground motion intensity factors of $25 \%, 300 \%$, and $500 \%$ to investigate the dynamic responses of specimens under slight, extensive and complete damage level, respectively. The experimental results show that corrosion changes the failure mode and significantly reduces the strength and drift capacity (plastic deformation capacity) of the corroded RC columns (about 50\% mass loss results in about $80 \%$ strength reduction).

\section{Experimental programme}

\subsection{Specimen preparation}

Three lightly confined RC columns representing non-code conforming [i.e. Eurocode 8 (CEN.EN 2010)], bridge piers are constructed. The specimens are cast in a $1500 \mathrm{~mm} \times 700 \mathrm{~mm} \times 300 \mathrm{~mm}$ foundation. The columns have a square cross-section of $250 \mathrm{~mm} \times 250 \mathrm{~mm}$ and $2300 \mathrm{~mm}$ height. It is worth mentioning that the aspect ratio is relatively large compared with typical bridge piers. This is because (1) the focus of these tests is on flexural dominant RC columns, and hence, large aspect ratio can guarantee the specimens will fail in flexure, and (2) due to the capacity limit of the shaking table, the axial load applied in this work cannot generate sufficient damage to RC columns with low 
aspect ratios. Eight reinforcing bars with a diameter of $16 \mathrm{~mm}$ are used in the vertical reinforcement. The transverse reinforcements are made of $8 \mathrm{~mm}$ diameter bars with $200 \mathrm{~mm}$ spacing along with the column height (as shown in Fig. 1). The ratio of the transverse bar/tie reinforcement spacing (confining reinforcement) and the diameter of the vertical reinforcement is 12.5, which are more spaced than recommended value of 6 in Eurocode 8 (CEN.EN 2010). The insufficient spacing of tie reinforcement makes the three specimens represent non-code conforming $\mathrm{RC}$ columns. The average concrete strength of $40 \mathrm{MPa}$ is derived by compressive tests conducted on three concrete cylinders. All steel reinforcement used in these tests is manufactured under the requirement of the British standard B500 (2005). Three tensile, compressive and cyclic tests are conducted on sample longitudinal bars to characterise their mechanical properties including their stress-strain relationships. The mechanical properties of the longitudinal bars are summarised in Table 1. The identification of the three specimens is given in Table 2.

\subsection{Accelerated corrosion procedure (ACP)}

Developing naturally corroded RC structures is a time-consuming process. It usually takes several years to achieve significant corrosion of the metal components of RC structures. To accelerate the corrosion process in the laboratory environment, some artificial techniques have been used by other researchers, including the external current method (El Maaddawy and Soudki 2003), pre-admixed chlorides (El Maaddawy and Soudki 2003) and cyclic wetting and drying (Otieno et al. 2016). In this study, an accelerated corrosion procedure

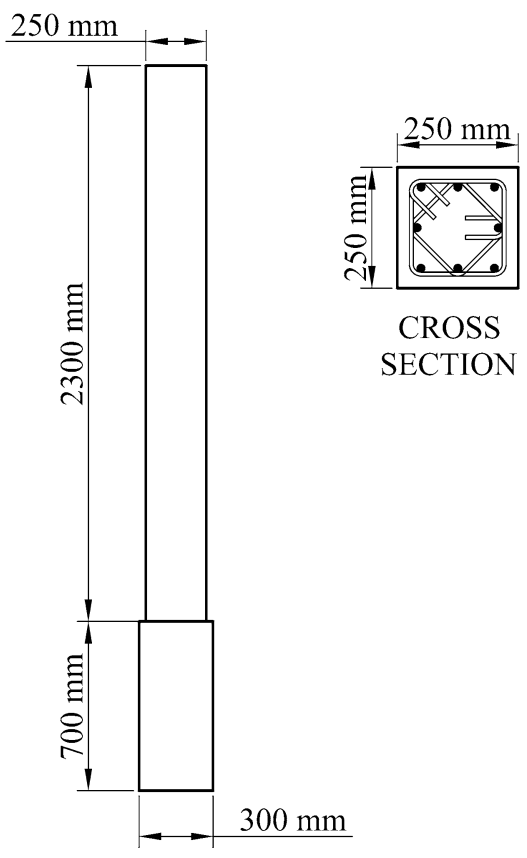

SIDE VIEW

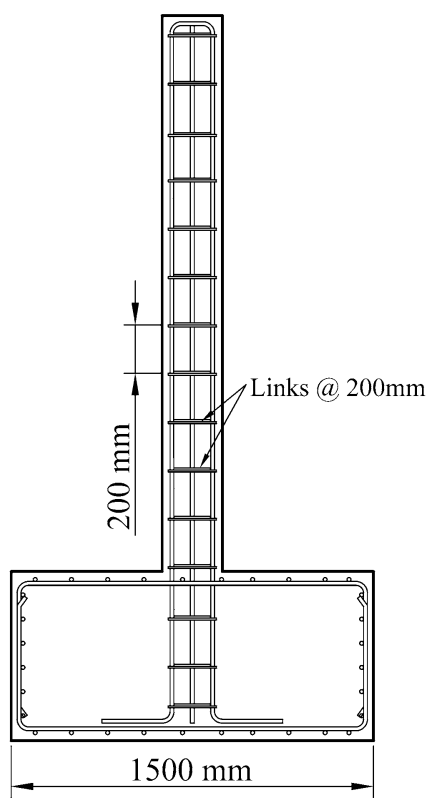

FRONT VIEW

Fig. 1 Reinforcement details of experimental test specimens 
Table 1 Mechanical properties of the specimens before being corroded

\begin{tabular}{llll}
\hline Bar diameter (D) & & $8 \mathrm{~mm}$ & $16 \mathrm{~mm}$ \\
\hline Yield strain & $\varepsilon_{y}$ & 0.00261 & 0.002733 \\
Yield stress (MPa) & $\sigma_{y}$ & 520 & 530 \\
Elastic modulus (MPa) & $\mathrm{E}_{s}$ & 200,426 & 193,913 \\
Hardening strain & $\varepsilon_{s h}$ & N/A & 0.02547 \\
Strain at maximum stress & $\varepsilon_{u}$ & 0.05660 & 0.164800 \\
Maximum stress (MPa) & $\sigma_{u}$ & 645 & 640 \\
Fracture strain & $\varepsilon_{r}$ & 0.151800 & 0.227350 \\
\hline
\end{tabular}

Table 2 The identification of the specimens

\begin{tabular}{llll}
\hline Column ID & UnCorr & Corr1 & Corr2 \\
\hline Corrosion variation & No corrosion & Lower corrosion & Higher corrosion \\
\hline
\end{tabular}

(ACP) using the external current method is employed to corrode the reinforcement inside $\mathrm{RC}$ columns. The external current method makes use of electrochemical theory to form an electrolytic cell where a redox reaction can occur when external electrical energy is supplied. Specifically, the reinforcing bars act as an anode, the external metal electrode act as a cathode, and the sodium chloride solution act as an electrolyte.

A polyethene pipe with $500 \mathrm{~mm}$ diameter and $1000 \mathrm{~mm}$ height was mounted on the top of the foundation to create a bath for the sodium chloride solution. Four $250 \mathrm{~mm} \times 1000 \mathrm{~mm}$ stainless plates are connected around the column as the cathode. Reinforcing bars and stainless plates are connected to the power supply by cables respectively. The sodium chloride solution contained $10 \%$ sodium chloride (i.e. salt). It is worth clarifying that no additional load (other than its own weight) is applied on the specimens during the procedure. The ACP setup is shown in Fig. 2.

The corrosion process was monitored by measuring the current in the circuit. Faraday's 2nd Law of Electrolysis illustrates the relation between mass loss and electric charge by Eq. (1). According to Eq. (2), the electric charge is determined by integrating the current over time. This method has been successfully used in other studies (Kashani et al. 2017a; Kashani 2017).

$$
\begin{gathered}
\Delta \mathrm{m}=\left(\frac{\mathrm{Q}}{\mathrm{F}}\right)\left(\frac{\mathrm{M}}{\mathrm{z}}\right) \\
\mathrm{Q}=\int_{0}^{\mathrm{T}} I \mathrm{~d} t
\end{gathered}
$$

where Q refers to total electric charge, $\mathrm{M}$ refers to the molar mass of the anode $(55.847 \mathrm{~g}$ for $\mathrm{Fe}$ ), $z$ is the ionic charge ( 2 electrons per $\mathrm{Fe}^{2+}$ in this case), $I$ is the measured current of the circuit and $T$ is the duration of corroding process. The ACP took 3 and 6 months for the Corr1 and the Corr2 specimens, respectively. During this period, the average measured currents are 1.39A (Corr1) and 1.37A (Corr2). Figure 3 shows the corrosion-induced damage to the RC columns after ACP. The horizontal and vertical cracks can be observed. This 


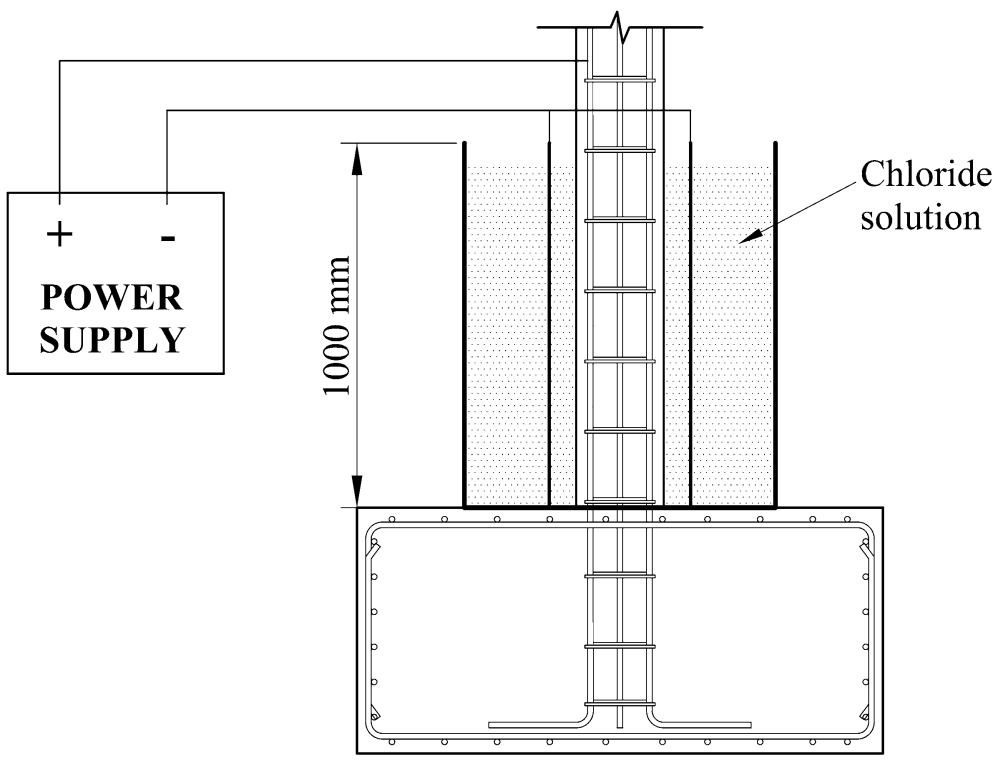

Fig. 2 Accelerated corrosion procedure setup

is because of the volumetric expansion of corrosion product resulting in internal pressure, which subsequently causes the concrete cover to crack along the reinforcement.

\subsection{Shaking table test}

The test programme is conducted on the shaking table facility at the University of Bristol. The table is $3 \mathrm{~m} \times 3 \mathrm{~m}$ and equipped with eight hydraulic actuators to provide a full six degrees of freedom. In this study, ground motions are applied in one direction, uniaxially. The specimen is fully fixed on the centre of the table with four angles and two channels to prevent the footing from horizontal and vertical movement. In consideration of the capacity limit of the shaking table, three metal mass blocks ( 1 tonne each) are attached rigidly on top of the column to generate the inertia force as well as axial load due to the mass of the deck on the column. It was expected that the corroded specimens may collapse during the tests. Therefore, a supporting frame was constructed and deployed around the column. To reduce the seismically induced overturning moments of the elevated mass on the table, four metal mass ( 1 tonne) blocks were attached to the corners of the table surface. Thus, uncontrolled and unwanted rocking motion of the shaking table under uniaxial excitation was avoided. The setup of the experimental rig is shown in Fig. 4. Accelerometers and cable extension position transducers were deployed on the specimen and the shaking table to track the movement during the test. The layout of the instrumentation is shown in Fig. 5. Six accelerometers are attached to the shaking table to track the movement in all 6 degrees of freedom. An accelerometer (ACC1) is mounted on the foundation of the specimen to record the acceleration of input ground motion. Two accelerometers (ACC2\&3) are attached at the top of the column to monitor the acceleration response in $x$ and $y$ directions. Two accelerometers (ACC6\&7) are fixed on the mass block in positive and negative $y$-axis respectively to 
(a)

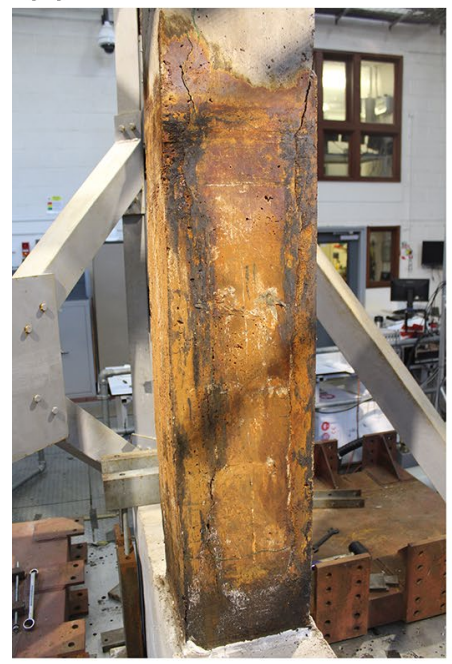

(c)

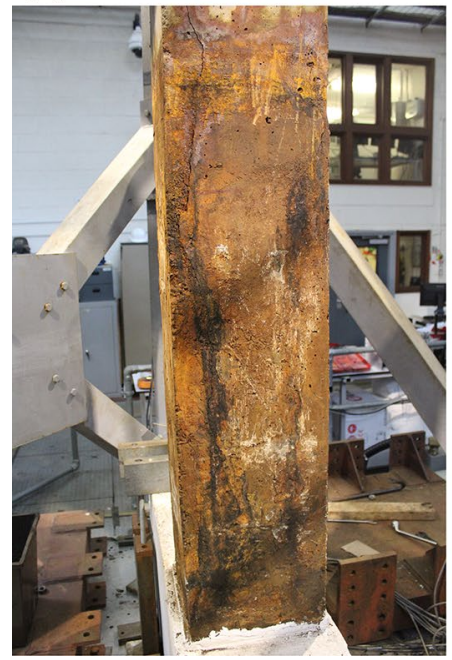

(b)

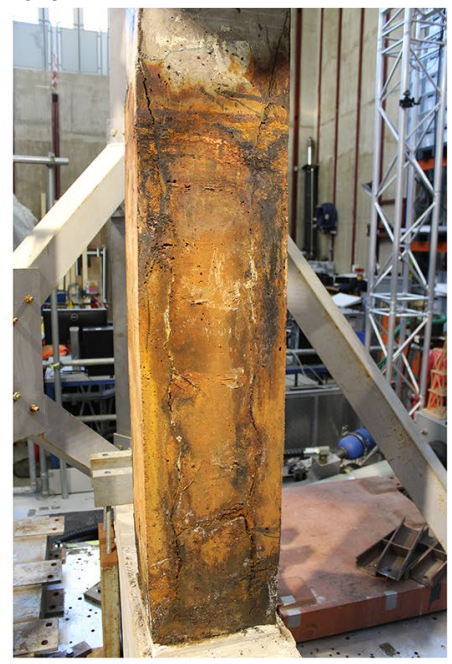

(d)

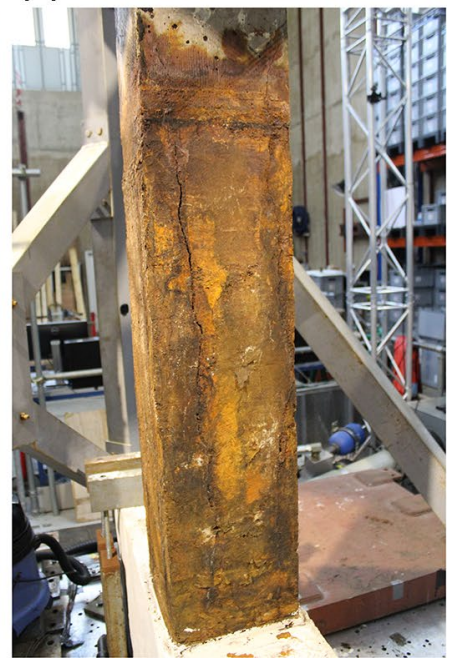

Fig. 3 Corrosion-induced cracks in Corr1 and Corr2 specimens: a, b front and back of Corr1, and $\mathbf{c}, \mathbf{d}$ front and back of Corr2

record the acceleration response on $x$-direction. The difference between the two acceleration time-histories can indicate the rotational movement of the specimen. Another two accelerometers (ACC4\&5) are set on the mass block to track the out-of-plane movement of the specimen. An accelerometer is fixed on the supporting frame to validate that the frame is rigid relative to the columns.

In the UnCorr column, a set of Linear Voltage Displacement Transducers (LVDT) were attached to the external face of the column to estimate flexural strains. However, the LVDTs were eliminated in the corroded columns as the extensive corrosion-induced damage to the concrete cover made these results unreliable as strain proxies. 
Fig. 4 Experimental test setup

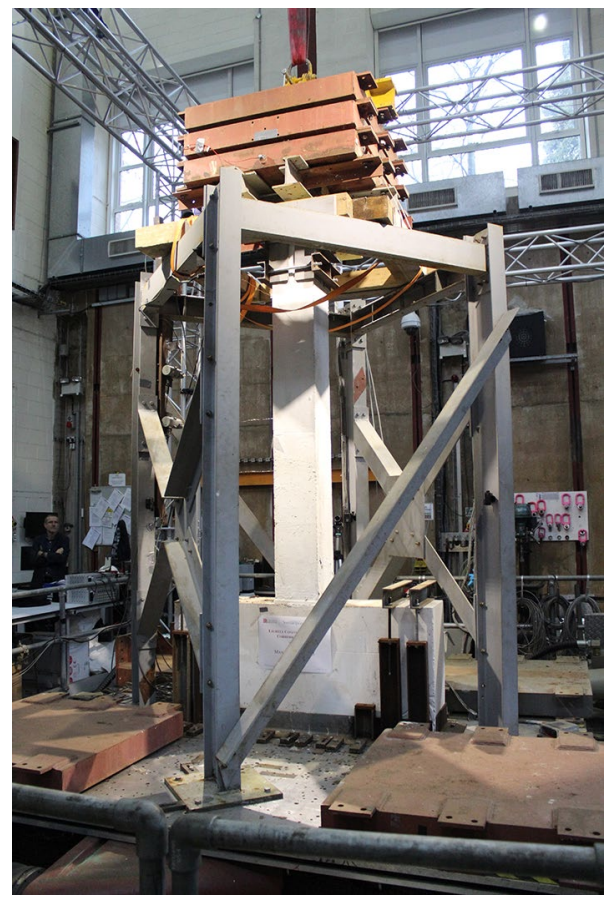

\subsection{Excitation ground motion}

The ground motion used in this study is selected from a set of ground motions taken from FEMA P695 (2009), which were previously used in a numerical exploration study (Kashani et al. 2017b). The spectrally matched Manjil earthquake (1990) is displayed in Fig. 6a [the ground motion is spectrally matched to mean response spectrum of all FF ground motions listed in FEMA P695 (2009)]. Figure 6b shows the response spectrum of the excitation ground motion together with the fundamental period of the UnCorr test specimen. Since the period of the tests specimen is within the maximum response spectrum of the proposed ground motion, there is no need to time-scale the ground motion (i.e. reducing the ground motion duration).

The aim is to explore the progressive damage of the corroded RC columns in the case of a cascade of increasing intensity events. This philosophy is also aligned with the pragmatism of extracting the maximum information from each specimen. Therefore, this cascade of earthquakes is represented with a series of increasing amplitude ground motion with scale factors of $25 \%, 300 \%$, and $500 \%$. These increasing amplitudes excitation time-series qualitatively representing slight, extensive and complete damage limit states respectively. System identification using very low-amplitude white-noise tests was performed on the specimen before the test and after each intensity level experiment. 


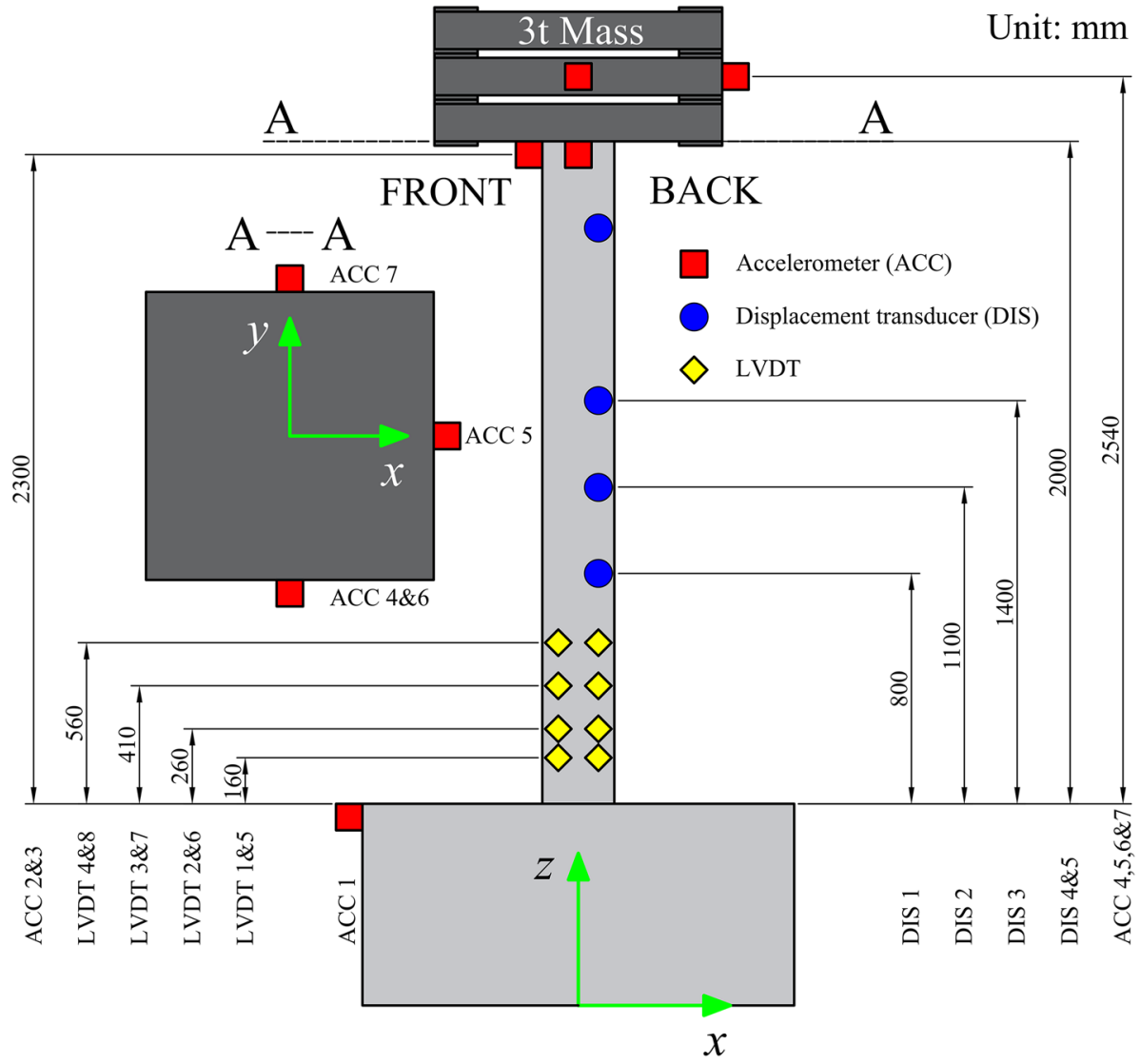

Fig. 5 Instrumentation layout

\section{Experimental results and discussion}

\subsection{Mass loss measurement and spatial variability of corrosion}

As mentioned above, the time-dependent corrosion induced mass loss is estimated by Faraday's second law of electrolysis [see Eq. (1)]. It has been reported that Faraday's law can give reliable values in lightly corroded specimens (El Maaddawy and Soudki 2003). However, the mass loss derived by Faraday's law, in this context, estimates the average mass loss of all the steel in the electrical circuit; i.e. both vertical and tie reinforcement. Equation (1) estimates the expected mass loss (i.e. the mean) but does not estimate the spatial variability of corrosion along the height of the columns. Therefore, further investigation of the spatial variability of corrosion is needed. After the shaking table tests were completed, the tested columns were demolished, and corroded bars were carefully taken out from the column. The cleaning procedure adapted by Kashani et al. (2013a, b) was used to remove the corrosion products (rust) and concrete from the corroded bars. The actual mass loss is estimated by calculating the ratio of the mass per unit length of corroded bars to their corresponding original mass per unit length before corrosion. The average mass loss ratios of 

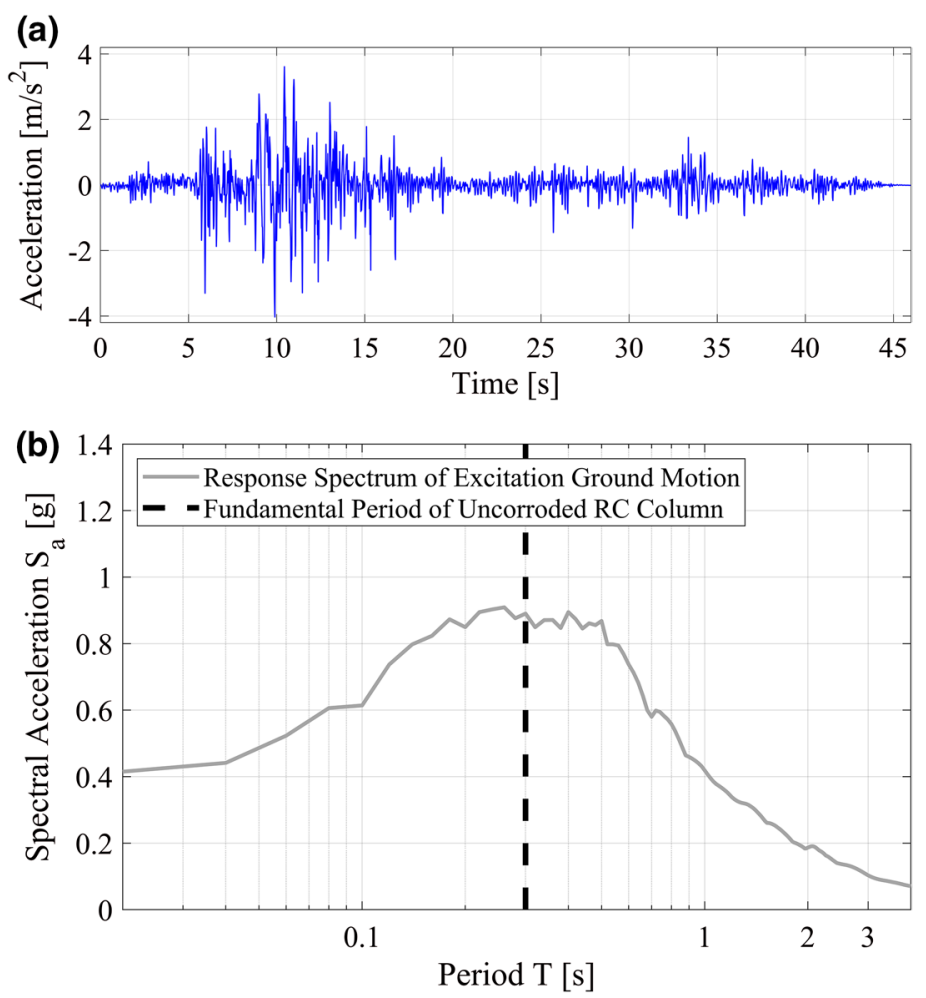

Fig. 6 Spectrally matched Manjil earthquake ground motion record: a acceleration time-series, and b elastic total acceleration response spectrum

the vertical bars in Corr1 and Corr2 specimens are $51 \%$ and $65 \%$ respectively. To quantify the spatial variability of corrosion along with the height of the columns, the vertical bars are cut in $200 \mathrm{~mm}$ segments (tie spacing) as shown in Fig. 7. The mass loss ratio of each segment is calculated separately (shown in the "Appendix"). In each segment, the mass loss ratios of the four vertical corner bars (No. 1, No. 3, No. 5 and No. 7) and mid-face bars were calculated separately as shown in Fig. 8. It should be noted that this method cannot reflect the influence of bar necking and elongation during the test. Regarding this point, a novel real-time spatial investigation method on steel bars is needed to improve the shaking table test on corroded RC structures in the future.

Figure 8 indicates clearly that the mass loss in the corner bars (bars 1, 3, 5 and 7 in Fig. 7) is larger than mid-face bars (bars 2, 4, 6 and 8 in Fig. 7). This is because the corner bars are exposed to bi-directional chloride diffusion, while the mid-face bars are exposed to unidirectional chloride diffusion. The synergistic effect of two-sided chloride ingress accelerates the corroding process, which leads to more deterioration and even earlier failure of the corner bars. This phenomenon is reported by other researchers (Lee et al. 2003; Khan et al. 2017). Zhang et al. (2011) conducted an experiment on fly ash concrete with two and three-dimensional chloride ingress. This finding is consistent with those summarised by Zhang et al. (2011).

As mentioned before, the designated part of the column to be corroded is $1 \mathrm{~m}$ above the foundation. It can be observed that the corrosion level reduces with increasing height 


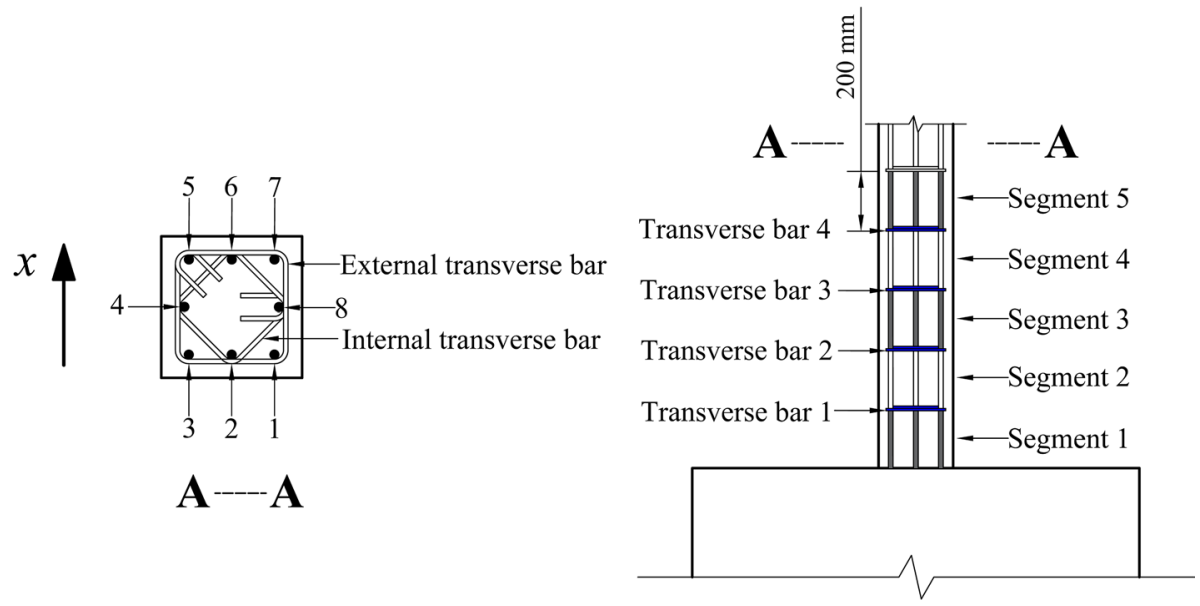

Fig. 7 Physical segments to investigate the spatial variability of corrosion

up the column in both specimens. In some part, such as segment $1 \& 2$ in Corr1 and segment 2 in Corr2, the bars have even disconnected after the corroding procedure. The same trend can be found on corroded tie reinforcement in both specimens. The outer face ties/ transverse bars (see Fig. 7) appears to have failed during the corroding process. Some of the interface ties/transverse bars remained functional during the corroding process, namely the one in the higher part of the column. Figure 9 displays the ties extracted from the two columns. It is clear from these results that there has been a substantial loss of confinement and a reduction in the lateral restraint against buckling of the main vertical reinforcement. Therefore, the drift capacity and strength of the columns was substantially reduced by the corrosion.

\subsection{Influence of corrosion on nonlinear hysteretic force-displacement response}

Using the recorded total acceleration and relative displacement (deformation) response time-histories of the tested specimen, the hysteretic cycles of force versus displacement are plotted and shown in Figs. 10, 11 and 12. The base shear is obtained by top block's mass ( 3 tonnes) plus the modal mass of the column itself, multiplied by the total acceleration response and normalised by the gravity load on the column. The lateral displacement is normalised to the column height (drift). Figure 10 shows the $25 \%$ (slight damage limit state) ground motion amplitude case. The UnCorr column shows almost linear response (Fig. 10a), while both corroded specimens (Fig. 10b, c) exhibited nonlinear responses at the same excitation level. The hysteretic loops in the corroded specimen at this level of excitation are mainly due to the corrosion-induced damage in concrete cover. The peak displacement response of Corr 1 and Corr 2 columns are $580 \%$ and $460 \%$ of the peak displacement of the reference column. Figure 10c shows that the force-displacement response of Corr2 column is unsymmetrical. The investigation of the spatial variability of corrosion showed that the vertical bars (bars 1,2 and 3 in Fig. 7) had more corrosion (see the table in "Appendix"), which resulted in an unsymmetrical hysteretic response. This nonuniform corrosion also resulted in some undesirable out of plane excitation of the corroded columns. 
Fig. 8 Spatial variability of corrosion damage at the lowest $1 \mathrm{~m}$ of corroded columns: a vertical bars in Corr1, $\mathbf{b}$ vertical bars in Corr2, and $\mathbf{c}$ transverse ties in both columns
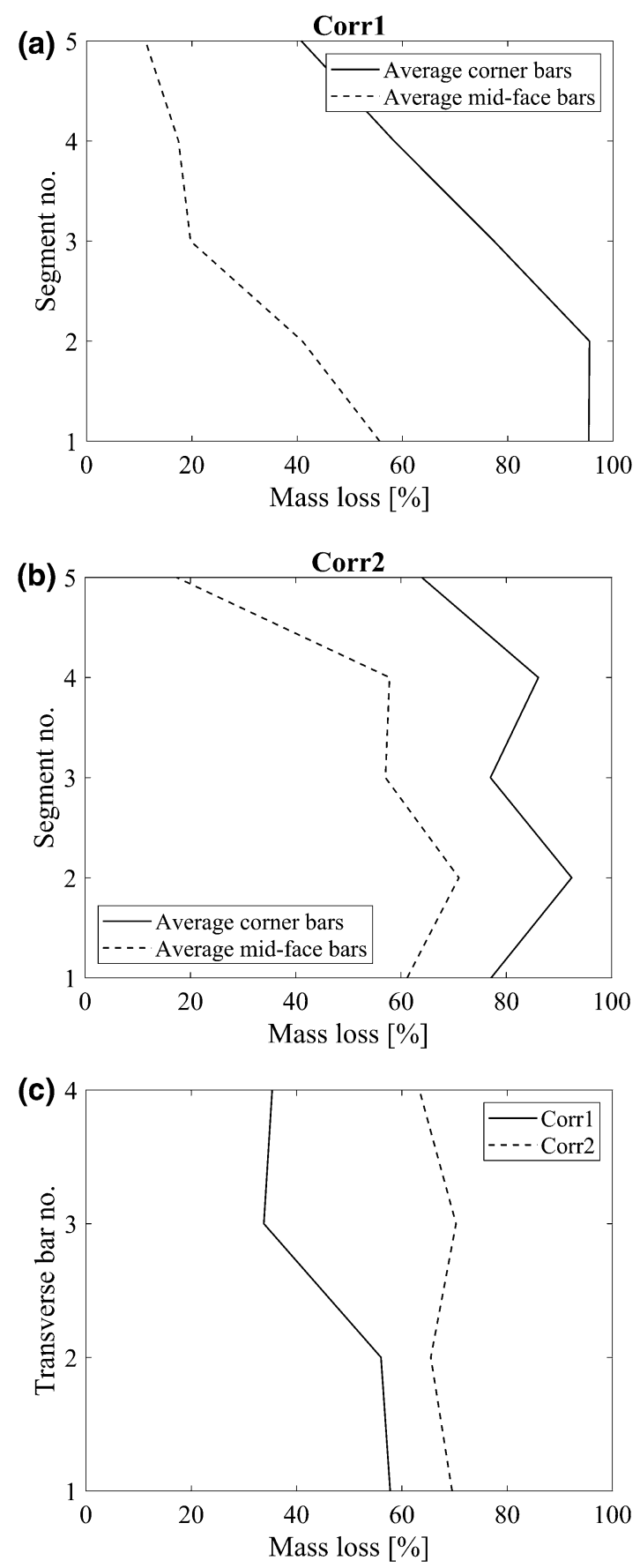

This is because the additional corrosion in the corner bars results in further corrosioninduced concrete cover cracking (as shown in Fig. 3), and hence, a significant reduction in concrete strength. Therefore, concrete cover crushes earlier on one side of the column, 
Fig. 9 Corrosion damaged transverse ties: a Corr1, and b Corr2
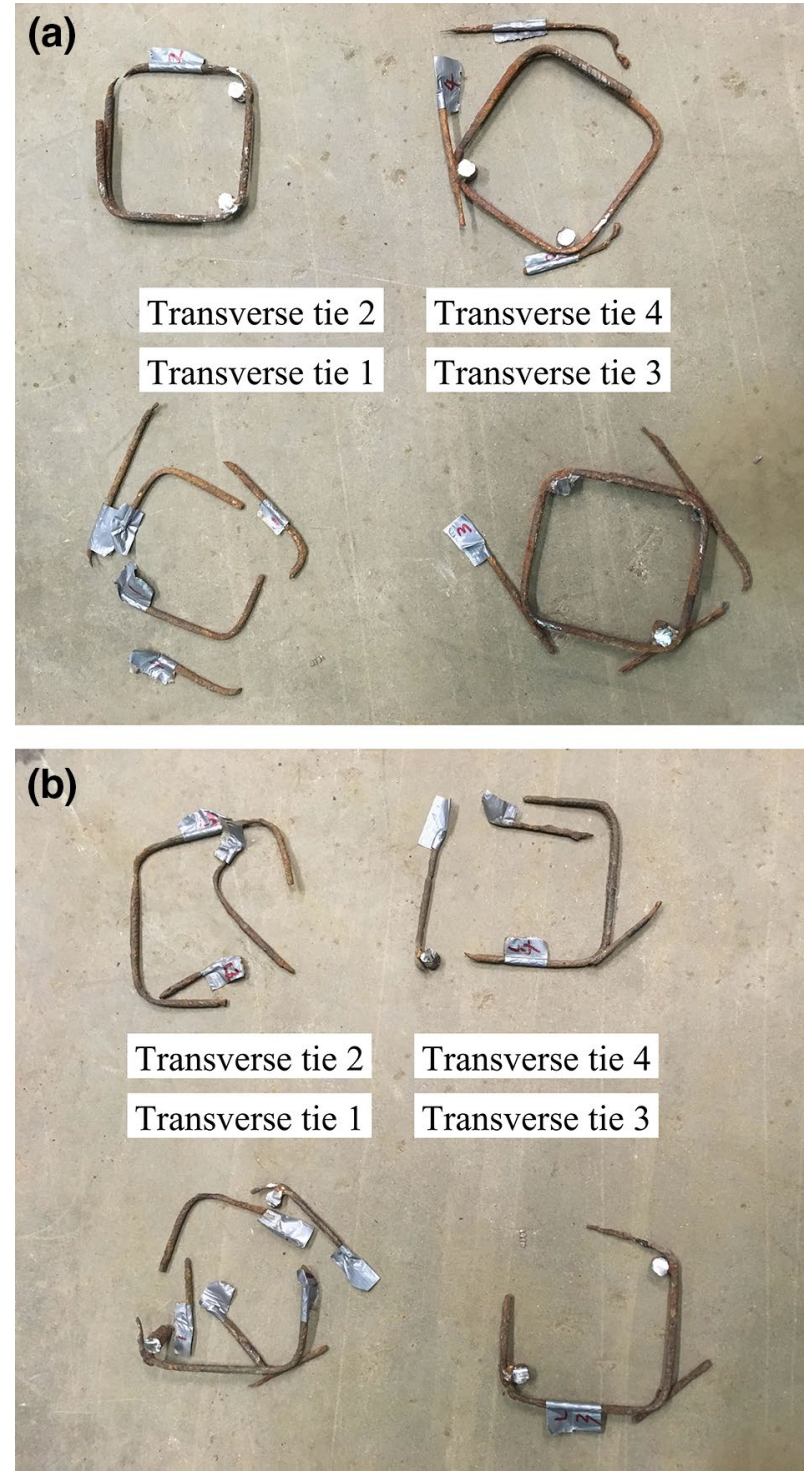

damage the reinforcing bars earlier, and hence, produces larger cyclic force-deformation loops. The corrosion-induced material (concrete cover and reinforcement) degradation also leads to the reduction of stiffness, which accounts for the larger displacement response observed in the two corroded specimens.

Figure 11 shows the force-displacement response of all three columns together with observed visual damage on tests specimen at this $300 \%$ excitation level. Figure 11a shows that the Corr 1 column collapses completely at the time of $10 \mathrm{~s}$. About $90 \%$ of lateral strength reduction is observed compared with the UnCorr control specimen. The Corr2 column (Fig. 11b), despite a slightly higher corrosion level (in terms of mass loss), 
Fig. 10 Force-displacement hysteretic response of all three columns at $25 \%$ excitation (slight damage): a Corr1, b Corr2, and c UnCorr
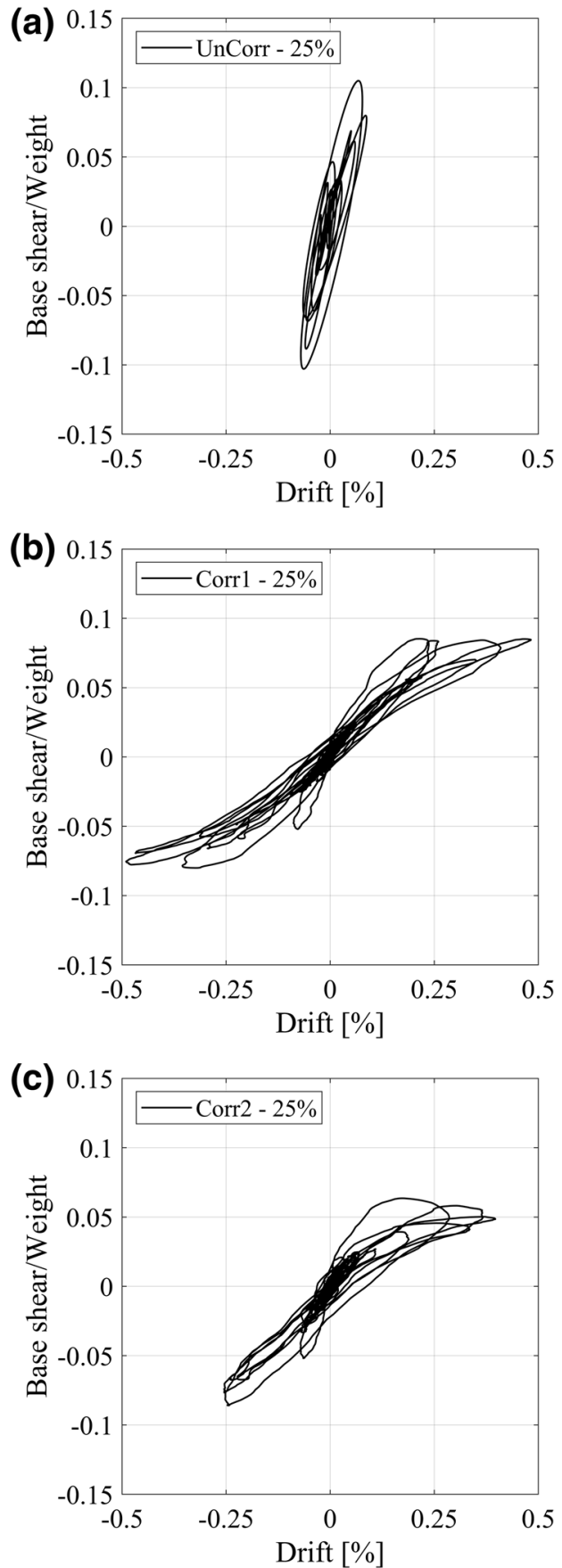

experiences severe damage without a complete collapse. Note that the mass loss measurements are averaged over $200 \mathrm{~mm}$ length of rebar. Therefore, it does not directly reflect the highly localised weakest point of the corroded RC columns. The spatial variability of 
pitting corrosion in vertical bars and tie reinforcement can greatly influence the failure mechanism of severely corroded RC columns.

The force-displacement response of the Corr2 column at $300 \%$ does not show the typical hysteretic response of RC components such as Lehman et al. (2004) and Kashani et al. (2019). During the test, at $300 \%$ excitation, some of the vertical bars fractured (due to a combination of pitting corrosion, tensile strain level, and low-cycle fatigue). Therefore, the response of Corr2 does not show the hysteretic response of a typical RC column. It was observed that the column was pivoting between the edges similar to a rocking column, and hence, resulting in concrete crushing in compression. In the hysteretic rocking response (Fig. 11c), force increases without an increase in displacement until it rocks, and as soon as the joint opens force significantly drops; i.e. negative stiffness (Makris and Vassiliou 2014). A rocking column system is typically characterised by a linear negative slope (negative tangent stiffness) of the force-deflection response (during the rocking phase). This negative tangent stiffness is observed in Fig. 11c in the high amplitude loops (for positive displacements). Furthermore, Fig. 11c shows that the hysteretic response is not symmetrical, which is due to a single-sided opening rocking which contains both in-plane and out-ofplane components. Figure 11d shows the observed damage in the UnCorr column, which is mainly due to inelastic buckling of vertical bars and premature crushing of core concrete. Figure 11e, f shows the observed damage in Corr1 and Corr 2 columns. Figure 11e shows that the complete collapse of Corr1 column is due to a severe loss of vertical reinforcement due to corrosion as well as corrosion-induced damage to the surrounding concrete. Figure $11 \mathrm{f}$ shows that the damage in Corr2 column is mainly at one side of the column, which justifies the unsymmetrical hysteretic response in Fig. 11c.

Figure 12 shows the force-displacement response of UnCorr and Corr2 columns (the Corr 1 column collapsed at $300 \%$ excitation) together with observed visual damage on tests specimen at $500 \%$ excitation level. Figure 12a shows the force-displacement response of the UnCorr level at the 500\% excitation level. The hysteretic response shows severe cyclic degradation, which is due to the inelastic buckling and low-cycle fatigue of vertical reinforcement. Figure $12 \mathrm{~b}$ shows that at the $500 \%$, the Corr 2 column exhibits an erratic force-displacement response, which includes an increasing residual tilting until the complete collapse at a time of $13 \mathrm{~s}$. $80 \%$ lateral strength reduction is observed compared with the UnCorr control specimen. This is before it is subjected to the largest-amplitude pulse of the ground motion. Figure 12c shows the observed damage in UnCorr column after the $500 \%$ excitation. The visual inspection of damage indicates that severe buckling of vertical bars in lightly confined columns which resulted in the premature crushing of core concrete previously at $300 \%$ excitation level results in severe buckling and large residual drift in the UnCorr column after the experiment. This consequently results in severe degradation in the hysteretic response of the column. Figure $12 \mathrm{~d}$ shows the completely collapsed Corr 2 column at 500\% excitation, which shows the unsymmetrical failure of the column. This is due to the unsymmetrical corrosion of vertical bars.

A further comparison of the results is provided in Fig. 13. It shows the hysteretic curves of all three columns at $25 \%$ excitation amplitude for the strong motion part of the response. It is evident from Fig. 13 that severe corrosion can result in a significant reduction in effective stiffness of RC columns. The severe reduction in stiffness results in an increase in drift, which subsequently results in the premature yielding of the longitudinal reinforcement and crushing of the cover concrete (as shown in Figs. 11, 12). The effective stiffness of the column greatly influences the dynamic properties of the structure as well as the strength and plastic deformation capacity, which all have a significant influence on the energy dissipation capacity of RC columns under earthquake loading. In the following sections of this 
Fig. 11 Force-displacement hysteretic response and observed damage of all three columns at 300\% excitation (extensive damage): a hysteretic response of UnCorr, b hysteretic response of Corr1, c hysteretic response of Corr2, $\mathbf{d}$ observed damage in UnCorr, e observed damage in Corr1, and $\mathbf{f}$ observed damage in Corr2

paper, we will quantitatively investigate the impact of corrosion on the effective stiffness and cumulative damage (energy dispassion) of the test specimens.

\subsection{Impact of corrosion and seismic damage on stiffness degradation and modal frequencies}

A transfer function estimate (based on both system input and output) is used to identify the current state of the system before and after every test. From this system identification, it is possible to estimate the combined influence of corrosion and structural damage on the system's natural frequencies and damping ratios. Therefore, a long duration (150 s) lowamplitude white-noise tests are conducted prior to the first experiment and after each excitation level experiment. The amplitude of $0.0043 \mathrm{~g}$ of the white-noise signal was chosen to avoid causing any significant concrete crack opening. This amplitude represents approximately $1 \%$ of PGA of the Manjil record (in Fig. 6). Therefore, the aim of these white noise tests was to produce a non-destructive system identification.

Power Spectral Density (PSD) of structural time-history records can extract structural characteristics in the frequency-domain (Cryer and Chan 2008). The transfer function (based on input and structural response accelerations time-series) are estimated using a MATLAB (1994-2018) toolbox (Vold et al. 1984), which employs Welch's algorithm (1967). Large peaks of the transfer function estimate modal frequencies. In this study, only the first and second modes are considered as shown in Fig. 14. Since the Corr1 specimen collapsed at $300 \%$ excitation, the white-noise tests data are not available at and beyond $300 \%$ excitation for this column.

Table 3 summarises the natural frequencies (mode $1 \& 2$ ) variation of the three specimens. The natural frequency (mode 1) of the UnCorr column is about $10 \%$ higher than the natural frequency of the corroded columns before the shaking table experiment. This shows that corrosion damage has some influence on the natural frequency of the corroded RC columns. After slight damage excitation level (25\% of PGA), all specimens exhibit further degradation in the frequency of their vibration modes. The natural frequency of the corroded columns reduces more rapidly than the UnCorr column. This is due to severe corrosion-induced damage. In contrast, the UnCorr column remains notionally elastic (see Fig. 10a). As expected, Fig. 14a, b shows a reduction in frequencies of columns after the earthquake excitation. Figure $14 \mathrm{c}$ shows the UnCorr column has higher natural frequencies than that of the Corr1 and Corr2 columns. However, Fig. 14d, unexpectedly, shows that after the $300 \%$ of PGA excitation test, column Corr2 has a higher frequency than the UnCorr column, which would appear to be counterintuitive. It is worth noting two points here (1) the force-displacement plots shown in Fig. 11 and post-experimental forensic examination indicate rebar fracture and a change system typology from flexural to a rocking column and (2) the amplitude of the white noise excitation may not have been sufficient to elicit rocking due to additional frictioninterlock between aggregate and corrosion products. This resulted in increased stiffness in the case of low amplitude excitations. The non-destructive (low-amplitude) white noise system identification tests characterise the system well for the case of systems 

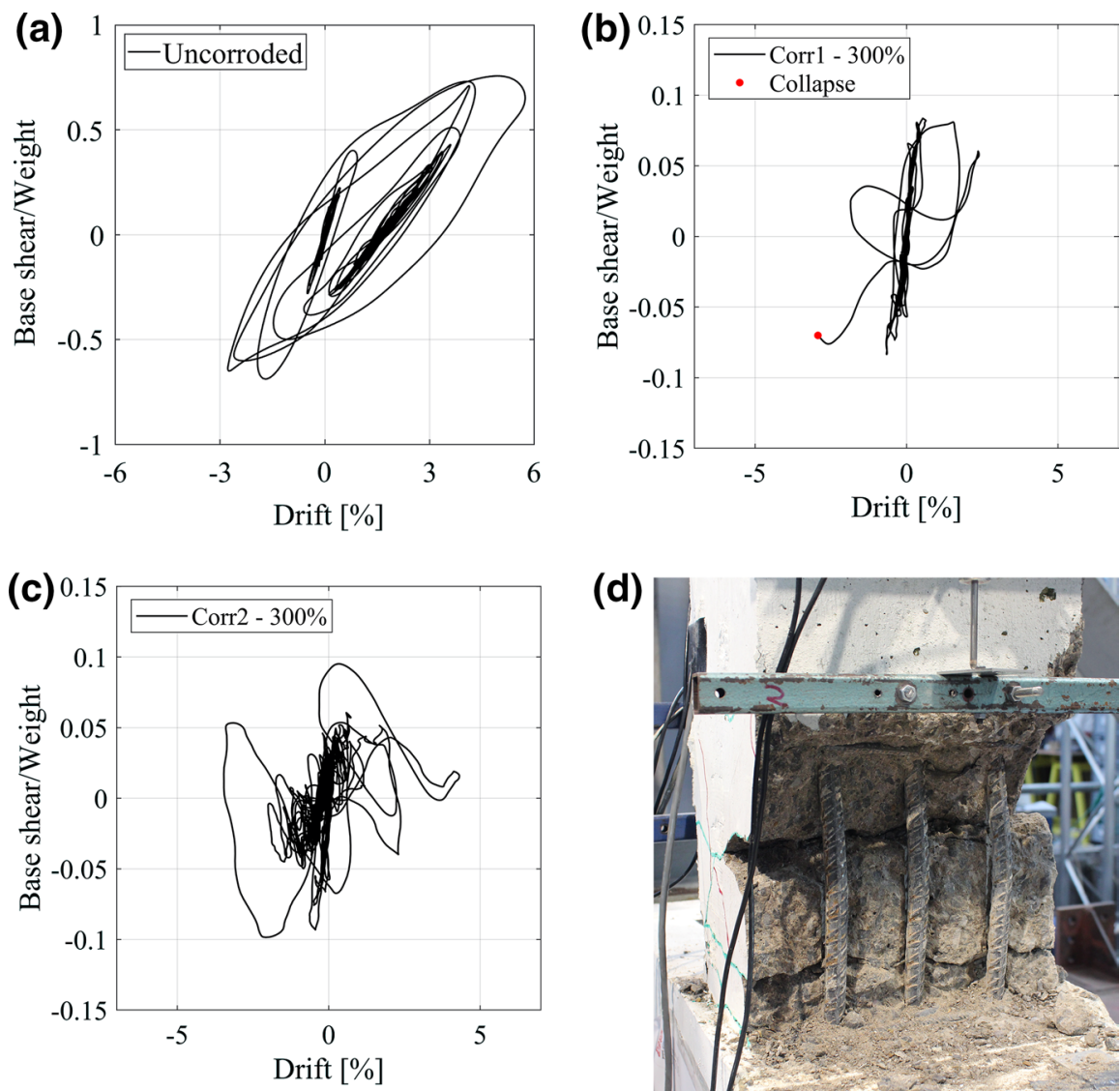

(d)

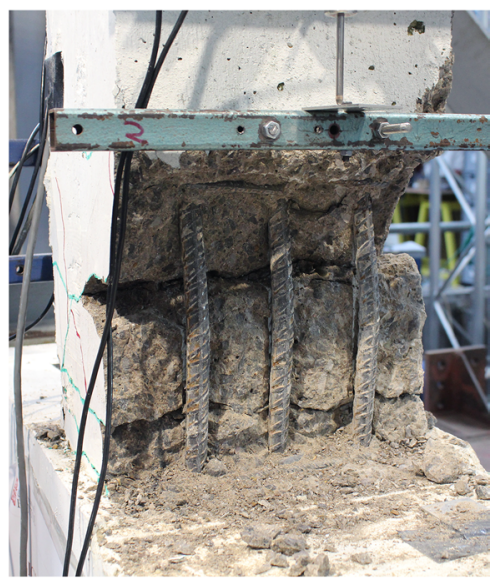

(e)

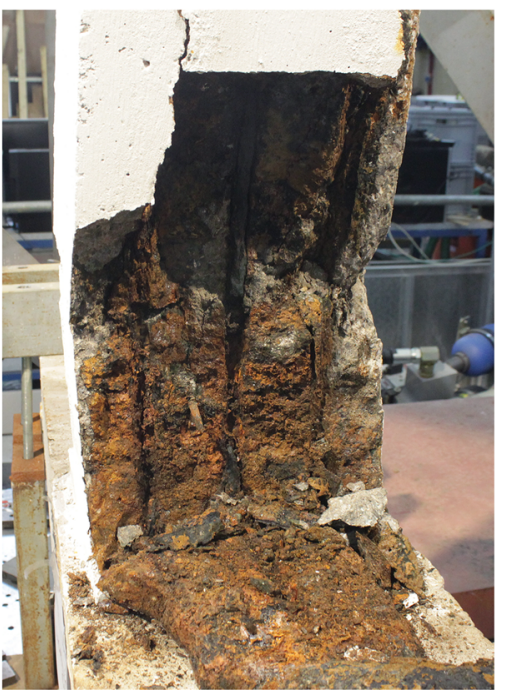

(f)

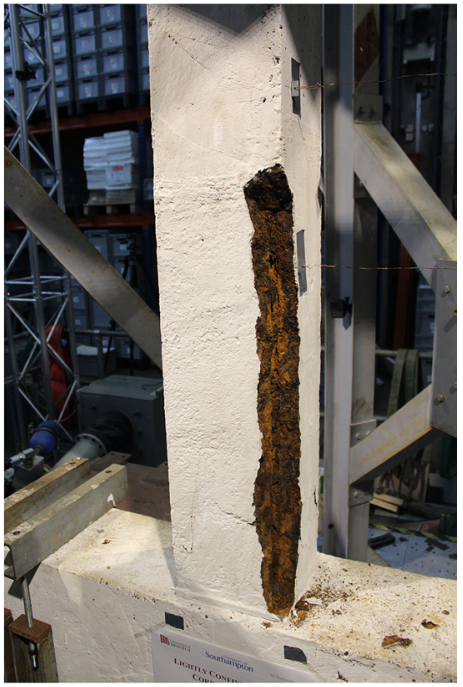




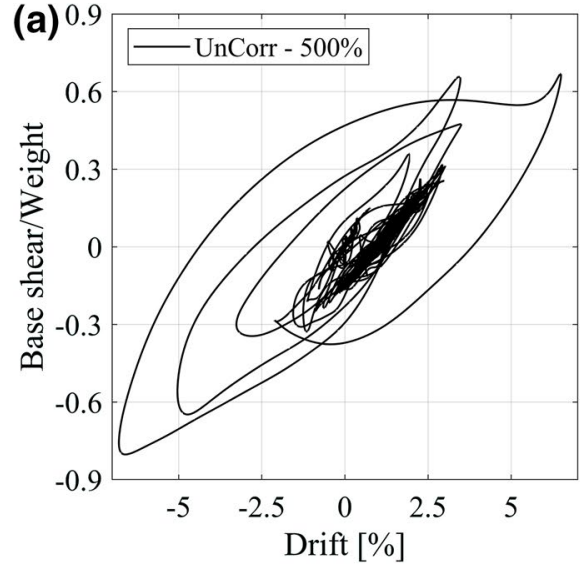

(c)

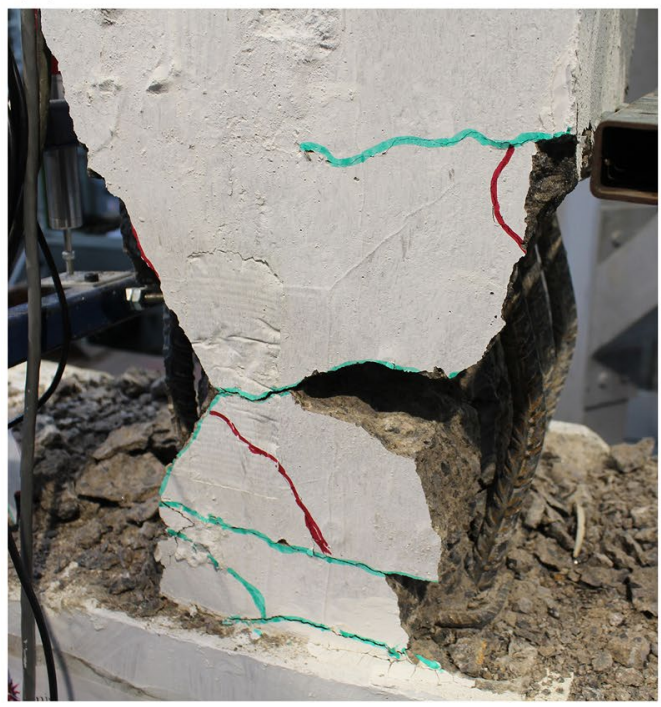

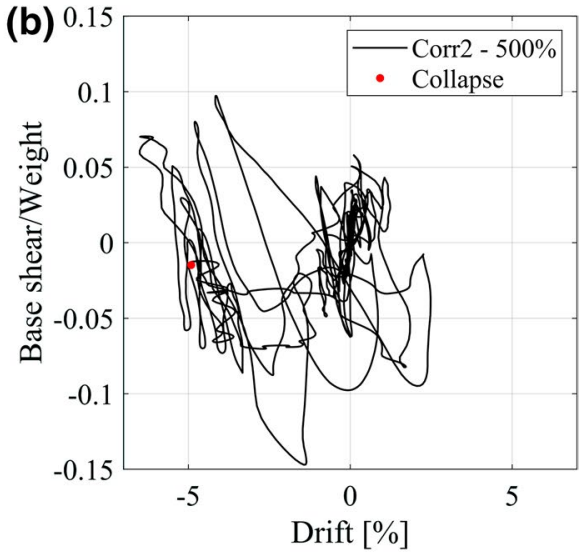

(d)

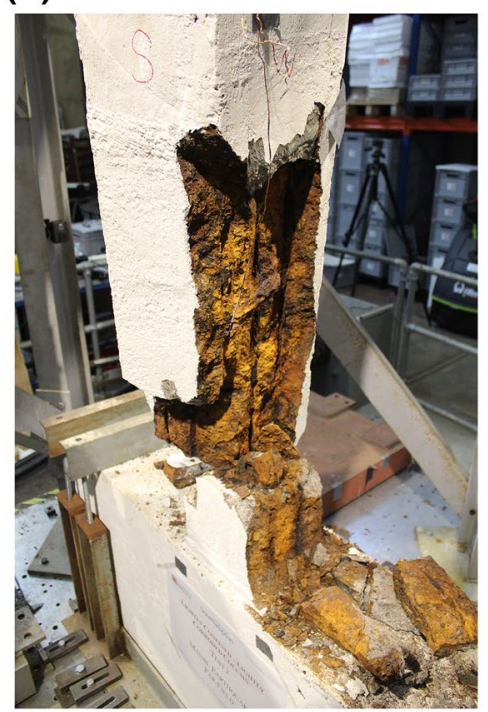

Fig. 12 Force-displacement hysteretic response and observed damage of UnCorr and Corr2 columns at $500 \%$ excitation (complete damage): a hysteretic response of UnCorr, b hysteretic response of Corr2, c observed damage in UnCorr, and $\mathbf{d}$ observed damage in Corr2

with low levels of damage. However, in this case (Corr2 after 300\% of PGA) we have a critically damaged column whose system characteristics are very sensitive to response amplitude levels. Therefore, if the aim is to characterise the extent of damage of a highly corroded/damaged system, then in situ ambient (low amplitude) system identification tests can produce ambiguous results that are suggestive of smaller damage then is actually present.

Stiffness degradation is an important indicator of structural damage under seismic excitation. During earthquakes, RC structures lose their strength and stiffness due to concrete cover spalling, core concrete crushing, reinforcement yielding/fracture in tension (due to large strain and/or low-cycle fatigue degradation), and inelastic buckling in 
Fig. 13 Comparative forcedisplacement responses of all columns at $25 \%$ excitation level

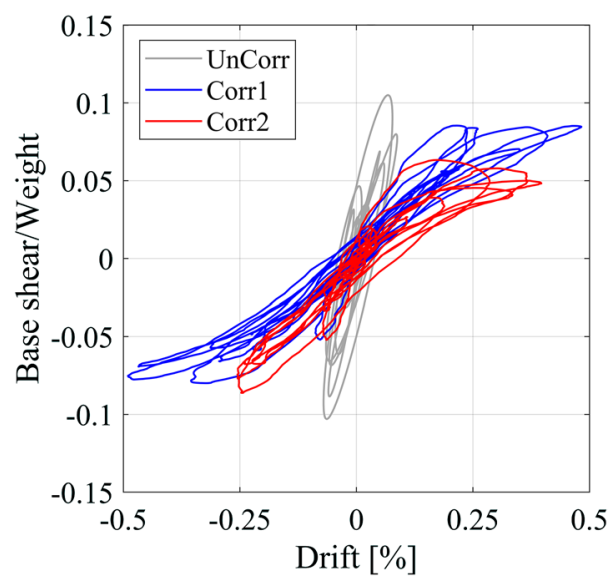

(b)

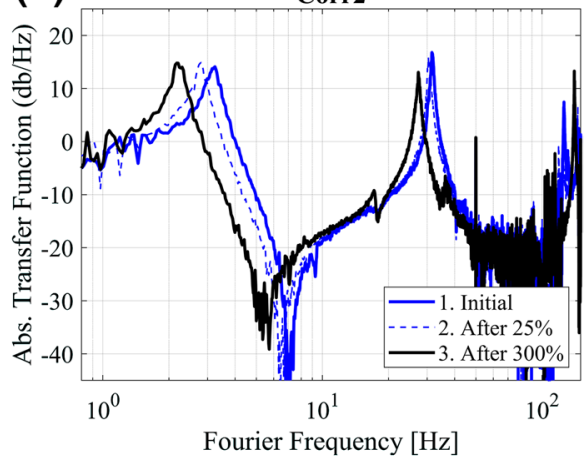

(d) Transfer functions (after 300\%)

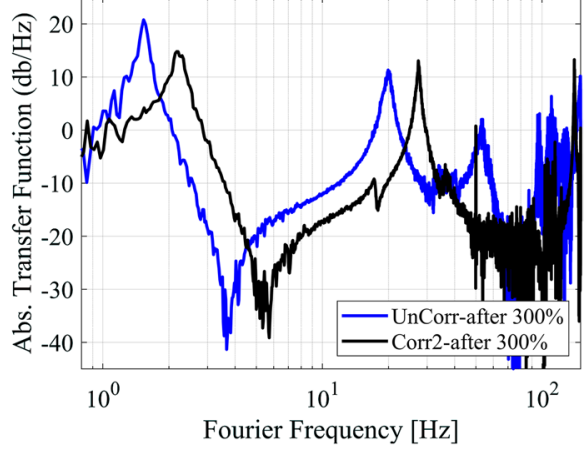

Fig. 14 Transfer function estimate of test specimens using the low-amplitude white noise excitation: a Corr1, b Corr2, c all three columns, and d UnCorr and Corr2 after 300\% excitation

compression. As it is qualitatively shown in Fig. 13, corrosion has a significant negative impact on effective the stiffness of RC columns. Here, we will quantitatively show the stiffness degradation of test specimens during the earthquake excitation. 
Table 3 Natural frequencies of the specimens obtained by white-noise tests

\begin{tabular}{|c|c|c|c|c|c|c|c|c|}
\hline & \multicolumn{2}{|l|}{ Pristine } & \multicolumn{2}{|c|}{ After $25 \%$} & \multicolumn{2}{|c|}{ After $300 \%$} & \multicolumn{2}{|c|}{ After $500 \%$} \\
\hline & Mode 1 & Mode 2 & Mode 1 & Mode 2 & Mode 1 & Mode 2 & Mode 1 & Mode 2 \\
\hline UnCorr & 3.66 & 29.77 & 3.41 & 29.67 & 1.53 & 19.91 & 1.28 & 16.93 \\
\hline Corr1 & 3.21 & 27.56 & 2.71 & 26.36 & 0 & 0 & - & - \\
\hline Corr2 & 3.21 & 31.71 & 2.71 & 30.39 & 2.20 & 27.31 & 0 & $\begin{array}{l}0 \\
\text { Unit: } \mathrm{Hz}\end{array}$ \\
\hline
\end{tabular}

Given the base shear force and displacement response of column time-histories, a leastsquare linear fit over a moving window can be used to estimate the time-stiffness and time-frequency relationship during a test. A smoothing low-pass filter is also employed. This is, in effect, an autoregressive moving average (ARMA) type approach, which results in an instantaneous stiffness time-series. As the window length in the ARMA process increases the underline trend becomes smoother. However, this increased noise attenuation comes at a cost of a loss of the resolution in time. A reasonable compromise is obtained for these specimens with a window length between 3 and 9 s. Figure 15 shows the estimated time-varying stiffness and frequency responses for the two corroded columns and the uncorroded control column at $25 \%$ excitation amplitude (corresponds to Fig. 13). The ARMA method requires force and deflection response time-histories to obtain predominant time-frequency trendline during the earthquake. The results for the uncorroded column exhibit more noise in the time-series. This is mainly due to epistemic noise in the displacement measurements during the low amplitude vibration parts of the experiment. Note that the uncorroded column displacements (at $25 \%$ of PGA) are smaller than those of the corroded columns.

\subsection{Time-cumulative damage analysis}

The cumulative energy dissipation is an important quantitative indicator of cyclic degradation of a structure subjected to seismic excitation. Cumulative energy dissipation is defined as the integration of the area inside hysteretic force-displacement loops (Chopra 2007). In this study, the cumulative energy dissipation of two corroded RC columns and the UnCorr control column at slight (25\%) and extensive (300\%) damage excitation levels are estimated. The results are normalised by the total dissipated energy of the UnCorr control specimen in each round of the test (shown in Figs. 10, 11, 12). Corroded columns Corr1 and Corr2 exhibit 1.53 and 1.75 times the energy dissipation of the UnCorr column at (25\% of PGA). At the $300 \%$ of PGA level, both corroded columns are highly damaged and appear to dissipate much smaller energy than the UnCorr column. Column Corr1 technically fails at $10 \mathrm{~s}$ and would completely collapse if not for the support frame. Column Corr2 as previously discussed has transited from a flexural to a rocking typology and is also very near to collapse. This shows, that corrosion results in premature plastic deformation in the corroded columns and hence higher energy dissipation at low-amplitude excitation (Fig. 16a). However, owing to the corrosion-induced reduction in strength and plastic deformation capacity, there is a severe reduction in energy dissipation capacity at large amplitude excitation (Fig. 16b). 

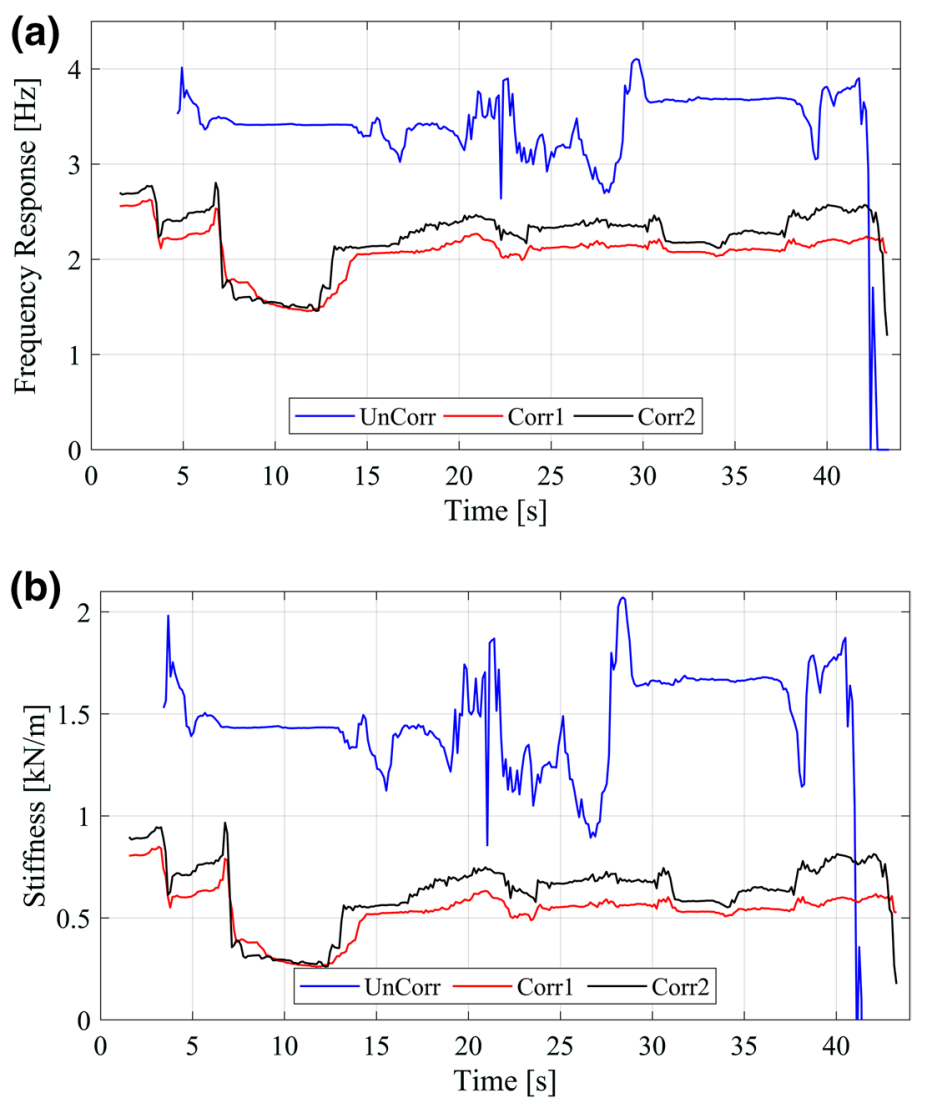

Fig. 15 Time-varying frequency and stiffness responses of all columns: a timefrequency response, and $\mathbf{b}$ time-stiffness response

\section{Conclusion}

This paper presents a set of shaking table tests on an UnCorr and two corroded RC columns to investigate the impact of corrosion on the nonlinear seismic performance of RC bridge piers. The two specimens are corroded using an accelerated corrosion procedure. They are tested under a far-field ground motion with increasing intensity scale factors until complete collapse. Spatial variability of corrosion, nonlinear hysteretic response, and structural stiffness and strength degradation are evaluated using the test results. Furthermore, timevarying stiffness analysis is conducted on the corroded and UnCorr columns and compared with each other. The experimental results showed a large scatter of data, which is due to the limitation in the number of experuimental test specimens, which requires further experimental testing in the future research. Nevertheless, this study provides a useful benchmarch experimental data that can be used in futur research by other researchers. The main findings of this research can be summarised as follows:

1. The pitting corrosion is spatially nonuniform along with the height and cross-section of the RC columns. In this study, it is observed that the pitting corrosion in the vertical 
Fig. 16 Normalised cumulative energy dissipation of the uncorroded and corroded columns: a slight damage excitation (25\%), and $\mathbf{b}$ extensive damage excitation $(300 \%)$

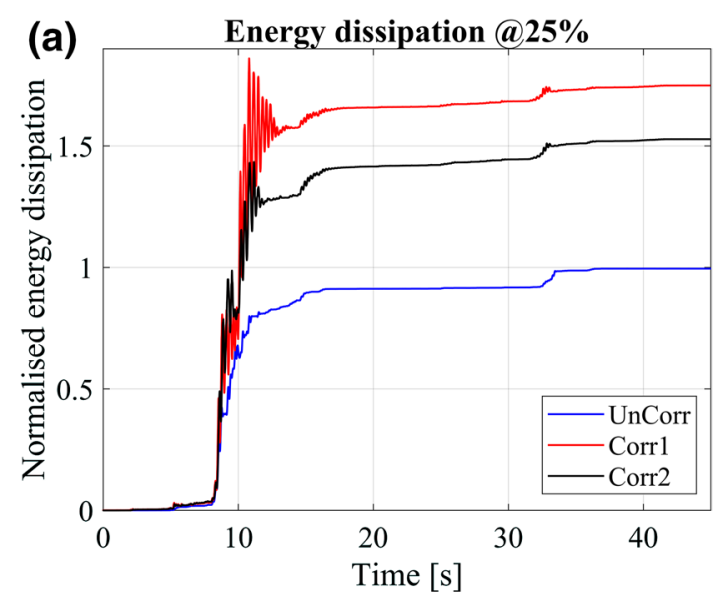

(b) $\quad$ Energy dissipation $@ 300 \%$

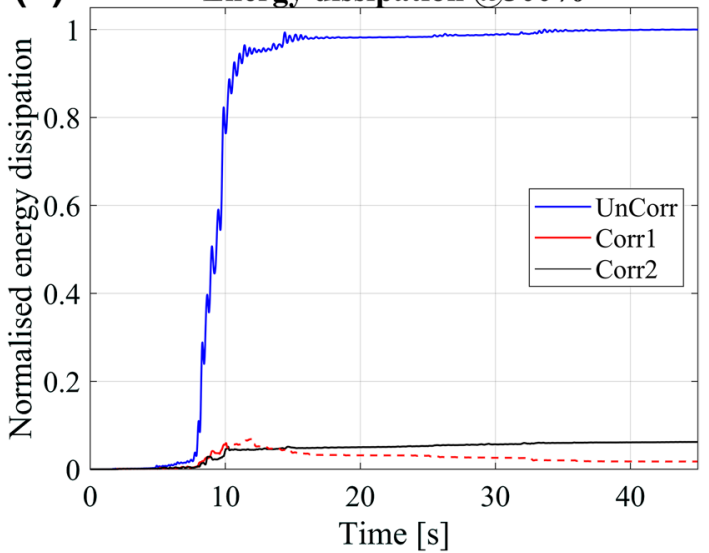

bars varies along with the column height. Furthermore, corner bars have more corrosion due to the two-dimensional diffusion of chloride ions. Some of the vertical rebars have corroded completely resulting in a broken (disconnected) segments of rebar imbedded in the concrete. The exterior tie reinforcement (with some failing) is more significantly corroded than the internal tie reinforcement as they are closer to the concrete surface.

2. The heavily corroded RC columns show significantly larger displacement responses than the UnCorr control column under the same seismic excitation, which is due to the corrosion-induced stiffness degradation. Premature nonlinear response and stiffness degradation can be detected when the seismic intensity is low, while the UnCorr control column with the same design remains elastic. The ultimate strength of the RC columns also significantly reduces by the corrosion damage (about $50 \%$ mass loss results in about $85 \%$ average reduction in this work).

3. Corrosion has a significant impact on the energy dissipation capacity and cumulative damage of RC columns in an earthquake with moderate intensity. It can be demonstrated that severely corroded RC columns exhibit far less energy dissipation capacity compared with UnCorr RC columns at high-amplitude excitation. This is primarily because at these excitation levels the presence of fractured corroded reinforcement permitted 
these columns to evolve their structural typology from a flexural inelastic column into a rocking column.

4. At small amplitude excitation levels, the UnCorr columns exhibit linear elastic responses while the corroded columns exhibit inelastic behaviour with unsymmetrical hysteretic force-displacement loops. Consequentially, at these small amplitude levels, the corroded columns exhibit large energy dissipation (a 50\% increase in energy dissipation) than the UnCorr column. This shows that even small magnitude earthquakes, which normally do not result in any significant damage in $\mathrm{RC}$ bridges, can result in severe damage in corroded RC bridges.

Open Access This article is distributed under the terms of the Creative Commons Attribution 4.0 International License (http://creativecommons.org/licenses/by/4.0/), which permits unrestricted use, distribution, and reproduction in any medium, provided you give appropriate credit to the original author(s) and the source, provide a link to the Creative Commons license, and indicate if changes were made.

\section{Appendix}

The following tables list the average mass loss in various segments of the columns as defined in mass loss measurement and spatial variability of corrosion section. Note that the (F) against a percentage indicates that there was a fracture, (a complete loss of continuity) of the bars.

See Tables 4, 5 and 6.

Table 4 The mass loss levels of the vertical bars of Corr1

\begin{tabular}{lllllllll}
\hline & Rebar 1 & Rebar 2 & Rebar 3 & Rebar 4 & Rebar 5 & Rebar 6 & Rebar 7 & Rebar 8 \\
\hline Segment 5 & $37.42 \%$ & $7.46 \%$ & $37.78 \%$ & $15.33 \%$ & $49.61 \%$ & $10.25 \%$ & $38.24 \%$ & $11.75 \%$ \\
Segment 4 & $59.68 \%$ & $16.96 \%$ & $60.06 \%$ & $16.41 \%$ & $50.02 \%$ & $18.02 \%$ & $63.87 \%$ & $18.48 \%$ \\
Segment 3 & $85.88 \%$ & $20.74 \%$ & $84.48 \%$ & $16.32 \%$ & $58.82 \%$ & $22.80 \%$ & $80.34 \%$ & $19.15 \%$ \\
Segment 2 & $100 \%(\mathrm{~F})$ & $43.34 \%$ & $100 \%(\mathrm{~F})$ & $34.33 \%(\mathrm{~F})$ & $82.13 \%$ & $56.81 \%(\mathrm{~F})$ & $100 \%(\mathrm{~F})$ & $29.5 \%$ \\
Segment 1 & $81.57 \%$ & $83.79 \%(\mathrm{~F})$ & $100 \%(\mathrm{~F})$ & $41.66 \%$ & $100 \%(\mathrm{~F})$ & $52.48 \%$ & $100 \%(\mathrm{~F})$ & $44.82 \%$ \\
\hline
\end{tabular}

Table 5 The mass loss levels of the vertical bars of Corr2

\begin{tabular}{|c|c|c|c|c|c|c|c|c|}
\hline & Rebar 1 & Rebar 2 & Rebar 3 & Rebar 4 & Rebar 5 & Rebar 6 & Rebar 7 & Rebar 8 \\
\hline $\begin{array}{l}\text { Segment } \\
5\end{array}$ & $80.83 \%$ & $22.80 \%$ & $\begin{array}{c}81.33 \% \\
\text { (F) }\end{array}$ & $17.05 \%$ & $28.26 \%$ & $15.22 \%$ & $65.24 \%$ & $14.31 \%$ \\
\hline $\begin{array}{l}\text { Segment } \\
4\end{array}$ & $100 \%(\mathrm{~F})$ & $\begin{array}{c}87.19 \% \\
\text { (F) }\end{array}$ & $\begin{array}{c}81.33 \% \\
\text { (F) }\end{array}$ & $46.83 \%$ & $75.41 \%$ & $45.34 \%$ & $87.56 \%$ & $51.92 \%$ \\
\hline $\begin{array}{l}\text { Segment } \\
3\end{array}$ & $77.81 \%$ & $100 \%(\mathrm{~F})$ & $\begin{array}{l}81.29 \% \\
(\mathrm{~F})\end{array}$ & $39.70 \%$ & $77.05 \%$ & $38.38 \%$ & $71.71 \%$ & $50.05 \%$ \\
\hline $\begin{array}{l}\text { Segment } \\
2\end{array}$ & $100 \%(\mathrm{~F})$ & $100 \%(\mathrm{~F})$ & $\begin{array}{c}81.29 \% \\
\text { (F) }\end{array}$ & $77.16 \%$ & $100 \%(\mathrm{~F})$ & $59.19 \%$ & $\begin{array}{c}88.32 \% \\
\text { (F) }\end{array}$ & $47.56 \%$ \\
\hline$\underset{1}{\text { Segment }}$ & $46.34 \%$ & $\begin{array}{c}80.46 \% \\
\text { (F) }\end{array}$ & $\begin{array}{c}81.29 \% \\
(\mathrm{~F})\end{array}$ & $\begin{array}{c}52.87 \% \\
(\mathrm{~F})\end{array}$ & $\begin{array}{c}86.83 \% \\
(\mathrm{~F})\end{array}$ & $\begin{array}{c}43.89 \% \\
(\mathrm{~F})\end{array}$ & $\begin{array}{c}93.94 \% \\
(\mathrm{~F})\end{array}$ & $67.43 \%(\mathrm{~F})$ \\
\hline
\end{tabular}


Table 6 The mass loss levels of transverse bars in Corr1 and Corr2

\begin{tabular}{lll}
\hline & Corr1 (\%) & Corr2 (\%) \\
\hline Transverse bar 4 & 35.37 & 63.33 \\
Transverse bar 3 & 33.78 & 70.29 \\
Transverse bar 2 & 56.04 & 65.49 \\
Transverse bar 1 & 57.78 & 69.54 \\
\hline
\end{tabular}

\section{References}

Alipour A, Shafei B, Shinozuka M (2010) Performance evaluation of deteriorating highway bridges located in high seismic areas. J Bridge Eng 16(5):597-611. https://doi.org/10.1061/(ASCE)BE.19435592.0000197

Almusallam AA (2001) Effect of degree of corrosion on the properties of reinforcing steel bars. Constr Build Mater 15(8):361-368. https://doi.org/10.1016/S0950-0618(01)00009-5

American Society of Civil Engineers (2013) Report card for America's infrastructure. http://www.infra structurereportcard.org/a/\#p/bridges. Accessed 05 Mar 2017

Balestra CE, Lima MG, Silva AR, Medeiros-Junior RA (2016) Corrosion degree effect on nominal and effective strengths of naturally corroded reinforcement. J Mater Civ Eng 28(10):04016103. https:// doi.org/10.1061/(ASCE)MT.1943-5533.0001599

British Standards Institution (BSI) (2005) Steel for the reinforcement of concrete-weldable reinforcing steel-bar, coil and decoiled product. British Standards 4449+A2, London, United Kingdom

Castel A, François R, Arliguie G (2000a) Mechanical behaviour of corroded reinforced concrete beams-part 1: experimental study of corroded beams. Mater Struct 33(9):539-544. https://doi. org/10.1007/BF02480533

Castel A, François R, Arliguie G (2000b) Mechanical behaviour of corroded reinforced concrete beams-part 2: bond and notch effects. Mater Struct 33(9):545. https://doi.org/10.1007/BF024 80534

Chiu CK, Tu FJ, Hsiao FP (2015) Lifetime seismic performance assessment for chloride-corroded reinforced concrete buildings. Struct Infrastruct Eng 11(3):345-362. https://doi.org/10.1080/15732 479.2014.886596

Chopra AK (2007) Dynamics of structures: theory and applications to earthquake engineering, vol 3. Pearson/Prentice Hall, Upper Saddle River

Cryer JD, Chan KS (2008) Time series analysis with applications in R. Springer, New York

Di Carlo F, Meda A, Rinaldi Z (2017) Numerical evaluation of the corrosion influence on the cyclic behaviour of RC columns. Eng Struct 153:264-278. https://doi.org/10.1016/j.engstruct.2017.10.020

Dizaj EA, Madandoust R, Kashani MM (2018a) Exploring the impact of chloride-induced corrosion on seismic damage limit states and residual capacity of reinforced concrete structures. Struct Infrastruct Eng 14(6):714-729. https://doi.org/10.1080/15732479.2017.1359631

Dizaj EA, Madandoust R, Kashani MM (2018b) Probabilistic seismic vulnerability analysis of corroded reinforced concrete frames including spatial variability of pitting corrosion. Soil Dyn Earthq Eng 114:97-112. https://doi.org/10.1016/j.soildyn.2018.07.013

Du YG, Clark LA, Chan AHC (2005a) Residual capacity of corroded reinforcing bars. Mag Concr Res 57(3):135-147. https://doi.org/10.1680/macr.2005.57.3.135

Du YG, Clark LA, Chan AHC (2005b) Effect of corrosion on ductility of reinforcing bars. Mag Concr Res 57(7):407-419. https://doi.org/10.1680/macr.2005.57.7.407

El Maaddawy TA, Soudki KA (2003) Effectiveness of impressed current technique to simulate corrosion of steel reinforcement in concrete. J Mater Civ Eng 15(1):41-47. https://doi.org/10.1061/ (ASCE)0899-1561(2003)15:1(41)

El Maaddawy T, Soudki K, Topper T (2005) Long-term performance of corrosion-damaged reinforced concrete beams. ACI Struct J 102(5):649

European Committee for Standardization (CEN.EN) (2010) Design of structures for earthquake resistance of structures-part 2: bridges. Eurocode 8, Brussels, Belgium

FEMA (2009) Quantification of building seismic performance factors. US Department of Homeland Security, FEMA. P695, Washington, DC 
Fernandez I, Bairan JM, Mari AR (2015) Corrosion effects on the mechanical properties of reinforcing steel bars. Fatigue and $\sigma-\varepsilon$ behaviour. Constr Build Mater 101:772-783. https://doi.org/10.1016/j. conbuildmat.2015.10.139

Fernandez I, Bairan JM, Mari AR (2016) Mechanical model to evaluate steel reinforcement corrosion effects on $\sigma-\varepsilon$ and fatigue curves. Experimental calibration and validation. Eng Struct 118:320-333. https://doi. org/10.1016/j.engstruct.2016.03.055

Ghosh J, Padgett JE (2010) Aging considerations in the development of time-dependent seismic fragility curves. J Struct Eng 136(12):1497-1511. https://doi.org/10.1061/(ASCE)ST.1943-541X.0000260

Ghosh J, Sood P (2016) Consideration of time-evolving capacity distributions and improved degradation models for seismic fragility assessment of aging highway bridges. Reliab Eng Syst Saf 154:197-218. https:// doi.org/10.1016/j.ress.2016.06.001

Guo A, Li H, Ba X, Guan X, Li H (2015a) Experimental investigation on the cyclic performance of reinforced concrete piers with chloride-induced corrosion in marine environment. Eng Struct 105:1-11. https://doi. org/10.1016/j.engstruct.2015.09.031

Guo A, Yuan W, Lan C, Guan X, Li H (2015b) Time-dependent seismic demand and fragility of deteriorating bridges for their residual service life. Bull Earthq Eng 13(8):2389-2409. https://doi.org/10.1007/s1051 8-014-9722-x

Kallias AN, Rafiq MI (2010) Finite element investigation of the structural response of corroded RC beams. Eng Struct 32(9):2984-2994. https://doi.org/10.1016/j.engstruct.2010.05.017

Kashani MM (2017) Size effect on inelastic buckling behavior of accelerated pitted corroded bars in porous media. J Mater Civ Eng 29(7):04017022. https://doi.org/10.1061/(ASCE)MT.1943-5533.0001853

Kashani MM, Crewe AJ, Alexander NA (2013a) Nonlinear cyclic response of corrosion-damaged reinforcing bars with the effect of buckling. Constr Build Mater 41:388-400. https://doi.org/10.1016/j.conbuildma t.2012.12.011

Kashani MM, Crewe AJ, Alexander NA (2013b) Nonlinear stress-strain behaviour of corrosion-damaged reinforcing bars including inelastic buckling. Eng Struct 48:417-429. https://doi.org/10.1016/j.engst ruct.2012.09.034

Kashani MM, Lowes LN, Crewe AJ, Alexander NA (2014) Finite element investigation of the influence of corrosion pattern on inelastic buckling and cyclic response of corroded reinforcing bars. Eng Struct 75:113125. https://doi.org/10.1016/j.engstruct.2014.05.026

Kashani MM, Alagheband P, Khan R, Davis S (2015a) Impact of corrosion on low-cycle fatigue degradation of reinforcing bars with the effect of inelastic buckling. Int J Fatigue 77:174-185. https://doi.org/10.1016/j. ijfatigue.2015.03.013

Kashani MM, Lowes LN, Crewe AJ, Alexander NA (2015b) Phenomenological hysteretic model for corroded reinforcing bars including inelastic buckling and low-cycle fatigue degradation. Comput Struct 156:58-71. https://doi.org/10.1016/j.compstruc.2015.04.005

Kashani MM, Lowes LN, Crewe AJ, Alexander NA (2016a) Computational modelling strategies for nonlinear response prediction of corroded circular RC bridge piers. Adv Mater Sci Eng. https://doi. org/10.1155/2016/2738265

Kashani MM, Lowes LN, Crewe AJ, Alexander NA (2016b) Nonlinear fibre element modelling of RC bridge piers considering inelastic buckling of reinforcement. Eng Struct 116:163-177. https://doi.org/10.1016/j. engstruct.2016.02.051

Kashani MM, Crewe AJ, Alexander NA (2017a) Structural capacity assessment of corroded RC bridge piers. Proc ICE Bridge Eng 170(1):28-41

Kashani MM, Málaga-Chuquitaype C, Yang S, Alexander NA (2017b) Influence of non-stationary content of ground-motions on nonlinear dynamic response of RC bridge piers. Bull Earthq Eng 15(9):3897-3918. https://doi.org/10.1007/s10518-017-0116-8

Kashani MM, Ge X, Dietz MS, Crewe AJ, Alexander NA (2019) Significance of non-stationary characteristics of ground-motion on structural damage: shaking table study. Bull Earthq Eng. https://doi.org/10.1007/ s10518-019-00668-3

Khan MU, Ahmad S, Al Gahtani HJ (2017) Chloride-induced corrosion of steel in concrete: an overview on chloride diffusion and prediction of corrosion initiation time. Int $\mathrm{J}$ Corros. https://doi. org/10.1155/2017/5819202

Lee HS, Kage T, Noguchi T, Tomosawa F (2003) An experimental study on the retrofitting effects of reinforced concrete columns damaged by rebar corrosion strengthened with carbon fiber sheets. Cem Concr Res 33(4):563-570. https://doi.org/10.1016/S0008-8846(02)01004-9

Lehman D, Moehle J, Mahin S, Calderone A, Henry L (2004) Experimental evaluation of the seismic performance of reinforced concrete bridge columns. J Struct Eng 130(6):869-879. https://doi.org/10.1061/ (ASCE)0733-9445(2004)130:6(869) 
Li X, Liang YS, Zhao ZH, Lv HL (2015) Low-cycle fatigue behavior of corroded and CFRP-wrapped reinforced concrete columns. Constr Build Mater 101:902-917

Li D, Wei R, Xing F, Sui L, Zhou Y, Wang W (2018) Influence of Non-uniform corrosion of steel bars on the seismic behavior of reinforced concrete columns. Constr Build Mater 167:20-32

Lim S, Akiyama M, Frangopol DM, Jiang H (2017) Experimental investigation of the spatial variability of the steel weight loss and corrosion cracking of reinforced concrete members: novel X-ray and digital image processing techniques. Struct Infrastruct Eng 13(1):118-134

Liu X, Jiang H, He L (2017) Experimental investigation on seismic performance of corroded reinforced concrete moment-resisting frames. Eng Struct 153:639-652

Ma Y, Che Y, Gong J (2012) Behavior of corrosion damaged circular reinforced concrete columns under cyclic loading. Constr Build Mater 29:548-556. https://doi.org/10.1016/j.conbuildmat.2011.11.002

Makris N, Vassiliou MF (2014) Dynamics of the rocking frame with vertical restrainers. J Struct Eng 141(10):04014245. https://doi.org/10.1061/(ASCE)ST.1943-541X.0001231

Mangat PS, Elgarf MS (1999) Flexural strength of concrete beams with corroding reinforcement. ACI Struct J 96(1):149-158

MATLAB (1994-2018) R2017b. The MathWorks Inc

Meda A, Mostosi S, Rinaldi Z, Riva P (2014) Experimental evaluation of the corrosion influence on the cyclic behaviour of RC columns. Eng Struct 76:112-123. https://doi.org/10.1016/j.engstruct.2014.06.043

Ni Choine M, Kashani MM, Lowes LN, O’Connor A, Crewe AJ, Alexander NA, Padgett JE (2016) Nonlinear dynamic analysis and seismic fragility assessment of a corrosion damaged integral bridge. Int $\mathrm{J}$ Struct Integr 7(2):227-239. https://doi.org/10.1108/IJSI-09-2014-0045

Otieno M, Beushausen H, Alexander M (2016) Chloride-induced corrosion of steel in cracked concrete-part I: experimental studies under accelerated and natural marine environments. Cem Concr Res 79:373-385. https://doi.org/10.1016/j.cemconres.2015.08.009

Ou YC, Tsai LL, Chen HH (2012) Cyclic performance of large-scale corroded reinforced concrete beams. Earthq Eng Struct Dyn 41(4):593-604. https://doi.org/10.1002/eqe.1145

Ou YC, Susanto YTT, Roh H (2016) Tensile behavior of naturally and artificially corroded steel bars. Constr Build Mater 103:93-104. https://doi.org/10.1016/j.conbuildmat.2015.10.075

Rajput AS, Sharma UK (2018) Corroded reinforced concrete columns under simulated seismic loading. Eng Struct 171:453-463. https://doi.org/10.1016/j.engstruct.2018.05.097

Schmitt G (2009) Global needs for knowledge dissemination, research, and development in materials deterioration and corrosion control. World Corrosion Organization, New York

Taha NA, Morsy M (2016) Study of the behavior of corroded steel bar and convenient method of repairing. HBRC J 12(2):107-113. https://doi.org/10.1016/j.hbrcj.2014.11.004

Vold H, Crowley J, Rocklin GT (1984) New ways of estimating frequency response functions. Sound Vib 18(11):34-38

Vu NS, Yu B, Li B (2016) Prediction of strength and drift capacity of corroded reinforced concrete columns. Constr Build Mater 115:304-318. https://doi.org/10.1016/j.conbuildmat.2016.04.048

Webster M, Clark L (2000) The structural effect of corrosion - an overview of the mechanism. In: Proceedings of concrete communication. Birmingham, United Kingdom, pp 409-421

Welch P (1967) The use of fast Fourier transform for the estimation of power spectra: a method based on time averaging over short, modified periodograms. IEEE Trans Audio Electroacoust 15(2):70-73. https://doi. org/10.1109/TAU.1967.1161901

Yang SY, Song XB, Jia HX, Chen X, Liu XL (2016) Experimental research on hysteretic behaviors of corroded reinforced concrete columns with different maximum amounts of corrosion of rebar. Constr Build Mater 121:319-327. https://doi.org/10.1016/j.conbuildmat.2016.06.002

Zhang Y, Sun W, Chen S, Guo F (2011) Two-and three-dimensional chloride ingress into fly ash concrete. J Wuhan Univ Technol Mater Sci Ed 26(5):978-982. https://doi.org/10.1007/s11595-011-0348-4

Zhang WP, Chen H, Gu XL (2015a) Tensile behaviour of corroded steel bars under different strain rates. Mag Concr Res 68(3):127-140. https://doi.org/10.1680/macr.15.00062

Zhang X, Wang J, Zhao Y, Tang L, Xing F (2015b) Time-dependent probability assessment for chloride induced corrosion of RC structures using the third-moment method. Constr Build Mater 76:232-244. https ://doi.org/10.1016/j.conbuildmat.2014.10.039

Zhang D, Zhao Y, Jin W, Ueda T, Nakai H (2017) Shear strengthening of corroded reinforced concrete columns using pet fiber based composties. Eng Struct 153:757-765

Zhu W, François R (2014) Experimental investigation of the relationships between residual cross-section shapes and the ductility of corroded bars. Constr Build Mater 69:335-345. https://doi.org/10.1016/j.conbuildma t.2014.07.059 
Zhu W, François R, Poon CS, Dai JG (2017) Influences of corrosion degree and corrosion morphology on the ductility of steel reinforcement. Constr Build Mater 148:297-306. https://doi.org/10.1016/j.conbuildma t.2017.05.079

Publisher's Note Springer Nature remains neutral with regard to jurisdictional claims in published maps and institutional affiliations. 